\title{
Ethnomedical Knowledge among Slavic Speaking People in South Kosovo
}

\author{
Avni Hajdari ${ }^{1 \dagger}$, Andrea Pieroni ${ }^{2 \dagger}$, Mamta Jhaveri ${ }^{3}$, Behxhet Mustafa ${ }^{1}$, Cassandra L. Quave ${ }^{3,4^{*}}$
}

\begin{abstract}
Local natural resources play an important role in securing human health in the Balkans, particularly as a source of food and medicine. The aims of this study were to document the ethnomedical practices of Slavic speaking groups in South Kosovo and to compare these findings to other studies conducted in the Western Balkans. Field research was conducted over a series of trips in 2014. Semi-structured interviews in which respondents were asked to list local taxa used for food and/or medicine were conducted in six communities located in the municipalities of Prizren and Dragash. Prior informed consent was obtained and 91 people were interviewed. Voucher specimens of cited wild flora and fungi were collected and deposited in duplicate at the herbaria of the University of Prishtina (Kosovo) and Emory University (USA). A total of 1,050 use citations were recorded for the various uses of 119 species (4 fungi and 115 plants) for food and/or medicine. Additionally, the ethnomedical uses of 27 ingredients of animal, mineral or industrial origin were also documented. The greatest number of citations were for dermatological and food uses of local plants. The most common families reported were Rosaceae (18 species cited), Lamiaceae (16) and Asteraceae (10). Informant consensus regarding category of use was highest (Fic $\geq 0.85$ ) for the categories of oral health, dermatological, and otolaryngological applications. Both wild and locally cultivated plants continue to play an important role among various ethnic groups in South Kosovo, with 389 distinct applications documented in this study alone.
\end{abstract}

Keywords: Balkans; Traditional Ecological Knowledge; Medicinal Plants

\footnotetext{
${ }^{1}$ Department of Biology, Faculty of Mathematical and Natural Science, University of Prishtina 'Hasan Prishtina', Mother Theresa St. 10000 Prishtina, Kosovo

2 University of Gastronomic Sciences, Pollenzo, Italy

${ }^{3}$ Department of Dermatology, Emory University School of Medicine, Atlanta, GA, USA

${ }^{4}$ Center for the Study of Human Health, Emory University College of Arts and Sciences, Atlanta, GA, USA

* Corresponding author. $\square$ E-mail address: AH (avhajdari@hotmail.com), AP (a.pieroni@etnobotanica.de), MJ (mamta.jhaveri@gmail.com), BM (behxhetm@yahoo.com), CLQ (cquave@emory.edu)
} 


\section{INTRODUCTION}

Traditional ecological knowledge (TEK) of local resources is closely tied to community resilience and food security in the Balkans. Over the past decade, a number of studies have focused on the ethnobotanical documentation of TEK in the Balkan Peninsula as it pertains to the use of flora and fungi for food, handicrafts and medicine. Specific to the Western Balkans, extensive fieldwork has been conducted in Albania (Pieroni, Dibra et al. 2005, Pieroni 2008, Pieroni 2010, Pieroni, Cianfaglione et al. 2014, Quave and Pieroni 2014), Bosnia and Herzegovina (Redžić 2006, Redžić 2007, Šarić-Kundalić, Dobeš et al. 2010, ŠarićKundalić, Fritz et al. 2010), Croatia (Pieroni, Elena Giusti et al. 2003, Łuczaj, Fressel et al. 2013), Kosovo (Mustafa, Hajdari et al. 2011, Mustafa, Hajdari et al. 2011, Mustafa, Hajdari et al. 2012, Mustafa, Hajdari et al. 2015), Macedonia (Rexhepi, Mustafa et al. 2013. Pieroni, Rexhepi et al. 2013), Montenegro (Menković, Šavikin et al. 2011, Pieroni, Giusti et al. 2011), Serbia (Jarić, Popović et al. 2007, Šavikin, Zdunic et al. 2013, Jarić, Mitrović et al. 2014, Stevanović, Petrović et al. 2014, Zlatković, Bogosavljević et al. 2014, Jarić, Mačukanović-Jocić et al. 2015), but until now, research comparing traditional ethnomedical practices between Slavic speaking groups in Kosovo has not been carried out. Geographically, the Western Balkans represent a unique biocultural landscape, featuring extensive biological, cultural, and linguistic diversity across an area of just $213,320 \mathrm{~km}^{2}$.

Despite its small geographic size $(10,840$ $\mathrm{km2}$ ), Kosovo offers a unique hotspot of biocultural diversity for ethnobotanical study. While most of the country's landscape is dominated by two plains (the Kosovo plain in the north-eastern and Dukagjin Plain in the south-western), the Sharr Mountains form the southern border, shared with Marcedonia and Albania, and Albanian Alps form the western border, shared with Montenegro and Albania. These geographic features offer a range in elevation from 265 to 2,656 m.a.s.l., with the majority of the area lying between 500 to 1,500 m.a.s.l. These geographic features combined with its modified continental climate (including subMediterranean and alpine climatic zones) offer a rich range of habitats for a diverse flora to flourish. Although a complete floristic survey has not yet been conducted, it is estimated that there are between 2,8003,000 vascular plant species in Kosovo.

TEK concerning the medicinal use of local plants, fungi and animals and their byproducts was investigated in the territory of Prizren, which lies in the southern part of the Sharr Mountains (in Albanian known as Malet e Sharrit; in Serbo-Croatian as Šar Planina) and represent one of the main centers of biodiversity in Balkans. In recognition of the rich levels of biodiversity in this region, a 53,469 hectares region of the Sharr Mountains was declared a National Park.

Until the end of the World War II, healthcare in this region was almost entirely based on traditional medicine, and these traditions continued after the war as well. Healthcare was commonly attended to within the family, and all physical and mental illnesses were treated with traditional medicines and rituals. These folk-medical traditions continue even now, especially in the more mountainous and isolated areas. Local people have withstood the extreme conditions of this region for centuries including very harsh winters. Until very recent decades, limitations in infrastructure and communication forced local residents to be self-sufficient in the provision of their food 
and healthcare. As a result, their primary pharmacopoeia consisted of local medicinal plants. Previous ethnobotanical and ethnolinguistic studies conducted in Kosovo have demonstrated that medicinal plants still play a crucial role in the sphere of human health, especially in isolated rural areas (Sejdiu 1984, Mustafa, Hajdari et al. 2011, Mustafa, Hajdari et al. 2011, Mustafa, Hajdari et al. 2015).

Recently, local populations have been negatively affected by migration due to displacement and the harsh economic conditions caused by the last Kosovo War (1998-1999). Migration patterns contribute to the rapid decline of traditional knowledge and the vertical transmission of oral traditional knowledge from one generation to another.

In addition to the highly biodiverse characteristics of the region, it is also very rich in terms of cultural and linguistic diversity. This region was historically occupied by three great empires Byzantine, Roman, and Ottoman. During the periods of between the fall and rise of different empires, it was occupied primarily by Bulgarians and Serbs. Today, the area is populated by various ethno-linguistic groups: ethnic Albanians (who speak the Gheg dialect of Albanian, as opposed to Tosk Albanian typical of southern Albania), Serbs (who speak Serbian), Turks (who speak Turkish), Bosniaks (who speak Bosnian), Gorani (who speak a Slavic language or "Našinski", a Gora dialect similar to Bosnian), and Roma (who speak Romani). In 2014, the year of our field-study, the resident population of Kosovo was estimated to be 1.78 million, with $28 \%$ being of the age $0-14,65 \%$ at $15-64$, and $7 \%$ that were 65 years and older, with an average life expectancy of 79.4 years for women and 74.1 for men. Additional information concerning the geographic characteristics, population, cultural aspects and nature values of this region have been previously described.

In previous field studies, we analyzed the medical ethnobotany of Albanians and different ethnic groups living in Kosovo; here we focus on the medical and food ethnobotany of the Slavic speaking Bosniaks and Gorani (Muslims), Serbs (Christian Orthodox) and surrounding Albanians populations (Muslim) living in South Kosovo. As previously found in other works, the folk heritage of the medico-botanical resources among South Slavs is particularly rich when compared with that of other ethnic groups. It is for this reason that we pursued ethnomedical documentation in this area with these particular ethnic groups. The main aims of this study were to document the ethnomedical remedies (plants, animal, mineral substances and other materials found in nature) used among Slavic speaking groups in South Kosovo and to compare these findings across ethnic groups, as well as with the pre-existing ethnobotanical literature of the Western Balkans available in English.

\section{MATERIAL AND METHODS}

\section{Field Study}

Ethnobotanical field research was conducted in 6 villages belonging to the municipalities of Prizren (3 villages) and Dragash (3), located in Sharr Mountains, which are situated in the southern part of Kosovo.

Field studies were conducted over six day field trips in 2014 as part of a fieldwork training course with students from the University of Prishtina. The research team was divided into small groups consisting of 
one professor and 2-3 students (three groups in total) that interacted with either individual respondents or small focus groups of no more than 3 individuals. Prior informed consent was obtained prior to conducting interviews and all researchers adhered to the ethical guidelines of the International Society of Ethnobiology. In most cases, small group interviews were conducted with different members of the same family unit. Snowball sampling methods were used to recruit informants and we particularly focused on local people who regularly use natural resources for medicinal purposes.

TEK was recorded using semi-structured interviews with informants. In particular, informal conversations focused on the issue of local taxa traditionally used for food (esp. wild food sources) and medicine. We sought in particular the following information: respondent demographics (age, gender, and community of residence), local names of useful plants or fungi, part(s) used, means of preparation, means of administration, local folk uses of taxa. Special care was taken to specifically document individual responses to all questions. In other words, within a small group, each person was questioned concerning their knowledge and use of each material discussed. Data sets collected reflect TEK of each independent informant.

In total, data were collected from 91 respondents, all from Slavic speaking groups - 48 Bosniaks (24 male, 24 female), 27 Gorani (12 male, 15 female), and 12 Serbians ( 7 male, 7 female) - with the exception of two Albanian participants (1 male, 1 female). The respondents were older than 50 years (with a few exceptions), mainly engaged in agricultural activities, and typically inherited their ethnobotanical knowledge from their direct ancestors (parents, grandparents) via oral traditions.

\section{Biological Specimens}

During the interviews, fresh plants were collected to create voucher specimens for herbarium deposit and whenever possible, informants were followed into the field to show us the quoted species. Most plant species were collected while flowering. Taxonomic identification of plants was undertaken using relevant standard botanical literature of the area. Plant nomenclature largely follows the Flora Europaea, while plant family assignments follow the current Angiosperm Phylogeny Group IV guidelines. Fungal taxonomy was confirmed using MycoBank. Voucher specimens of the wild taxa were deposited at the University of Prishtina Herbarium and Emory University Herbarium (Index Herbarium code: GEO). Specimens are in the process of being digitized; full collection information and digital images can be accessed via the SERNEC portal.

\section{Data Analysis}

We analyzed the data collected in effort to assess TEK across ethnic groups in this highly biodiverse pocket of the Balkans. We have employed a number of tools in our quantitative analysis of the pooled data, described below.

\section{Use-Value Citation Index}

The Use-Value $\left(U V_{c}\right)$ citation index is useful for evaluating the relative importance of each species based on its cited uses . The $U_{\mathrm{c}}$ was calculated for all taxa as follows:

$$
U V_{c}=\frac{\sum U_{i s}}{N}
$$


where $U_{\text {is }}$ is the sum of the total number of all individual use citation reports concerning a given taxa, divided by the total number of informants $(\mathrm{N})$.

\section{Informant Consensus Factor}

The categories selected for use in the Informant Consensus Factor $\left(F_{\text {ic }}\right)$ analysis are provided in Table 1 and follow a previously described system. Each taxa use was added to the appropriate category prior to analysis using the following formula:

$$
F_{i c}=\frac{N_{u c}-N_{t}}{N_{u c}-1}
$$

where $\mathrm{N}_{\mathrm{uc}}$ is the total number of use citations in each category and $N_{t}$ is the number of taxa used in that category. High $F_{\text {ic }}$ values (near 1.0) are obtained when one or a few species are reported to be used by a large proportion of informants for a particular category, whereas lower $F_{\text {ic }}$ values indicate that informants disagree over which taxa to use.

\section{RESULTS}

A total of 119 species (4 fungal and 115 plant species), representing 4 fungal and 43 plant families (Figure 1) were cited for ethnopharmacological applications, ranging from health food to various forms of medicine. Emic categories of medicinal or other applications were determined based on analysis of informant reports on plant uses, and qualitative interpretation of local illness assignments based on body system (e.g., cardiovascular system, gastrointestinal, dermatological, etc.), as previously described in other work using $F_{\text {ic }}$ analysis. Seventy-one taxa were collected

Table 1. Ethnomedicine use reports

\begin{tabular}{l|l}
\hline \multicolumn{1}{c|}{ General Category of Use } & \multicolumn{1}{c}{ Examples of indications and uses } \\
\hline Cardiovascular & $\begin{array}{l}\text { Cardiotonic, hypertension, anemia, heart disorders, high cholesterol, } \\
\text { varicose veins, venous ulcers }\end{array}$ \\
\hline Dermatological & $\begin{array}{l}\text { Alopecia, anti-inflammatory, antiseptic, burns, contusions, dog bite, } \\
\text { eczema, circumcision, edema, facial rejuvenation, hair } \\
\text { strengthener/fortifier, infected wounds, laceration, psoriasis, scabies, } \\
\text { seborrheic dermatitis, warts, wounds }\end{array}$ \\
\hline Endocrine & Diabetes \\
\hline Food & Recreational tea, beverage, lacto-fermented food, vegetable pie \\
\hline General health & $\begin{array}{l}\text { Immune boosting, health promotion, weight loss, cleansing, recovery } \\
\text { from sports injuries, fever }\end{array}$ \\
\hline Gastrointestinal & $\begin{array}{l}\text { Appetite stimulant, stomach ache, internal haemorrhages, bloody } \\
\text { diarrhoea, constipation, digestive aid }\end{array}$ \\
\hline Neuromuscular & Neurorelaxant, anti-stress, insomnia, headache, rheumatic pain \\
\hline Ophthalmological & Conjunctivitis, eye inflammation \\
\hline Oral health & Toothache \\
\hline Otolaryngological & Ear infection \\
\hline Psychiatric & Anxiety, fear \\
\hline Respiratory & $\begin{array}{l}\text { Cough (antitussive), respiratory tract infection, asthma, expectorant, } \\
\text { bronchitis }\end{array}$ \\
\hline Urological & Urogenital disorders, kidney stones, urinary tract infections, diuretic \\
\hline Women's Health & $\begin{array}{l}\text { Fertility, difficult childbirth, galactagogue, menopause symptoms, } \\
\text { postpartum infection }\end{array}$ \\
\hline Veterinary care & Insect repellent, skin injury, wounds \\
\hline &
\end{tabular}

Legend: Division of ethnobotanical use reports by general categories for Informant Consensus Factor $\left(F_{i c}\right)$ analysis. 
from the wild, 42 were cultivated, 2 were semi-cultivated, 3 were purchased, and one was either wild harvested or cultivated. The most broadly represented plant families were Rosaceae (18 species cited), Lamiaceae (16 spp.) and Asteraceae (10 spp.) (Figure 1). Additionally, 13 ingredients of animal origin (Appendix I) and 14 of mineral or industrial origin (Appendix II) were spontaneously cited for medicinal applications, without specific questions to informants concerning the use of such materials.

The most frequently quoted manner of preparation of medicinal plants was represented by infusions $(58 \%)$, tropical application (15\%), decoction $(7 \%)$, macerations $(6 \%)$, eaten fresh (4\%) squeezed liquid (3\%) tincture (2\%), ointments $(2 \%)$ and others preparation with $1 \%$ or less (Figure 2). On the other hand, the most frequent food preparations were: tea $(35 \%)$, lacto-fermented products $(17 \%)$, fill for pies $(14 \%)$, jams $(8 \%)$, compote $(6 \%)$, alcoholic fermentation $5 \%$ and with $1 \%$ vinegar and 'ajvar' preparations (Figure 3).

The most frequently cited medicinal uses referred to dermatological disorders $(20 \%)$ gastrointestinal diseases (20\%), respiratory $(15 \%)$ troubles, gastrointestinal illness (12\%), illnesses, cardiovascular illness $(11 \%)$, etc. (Figure 4$) .72 \%$ of the plants were internally administered while 28 of the preparations were externally administered.
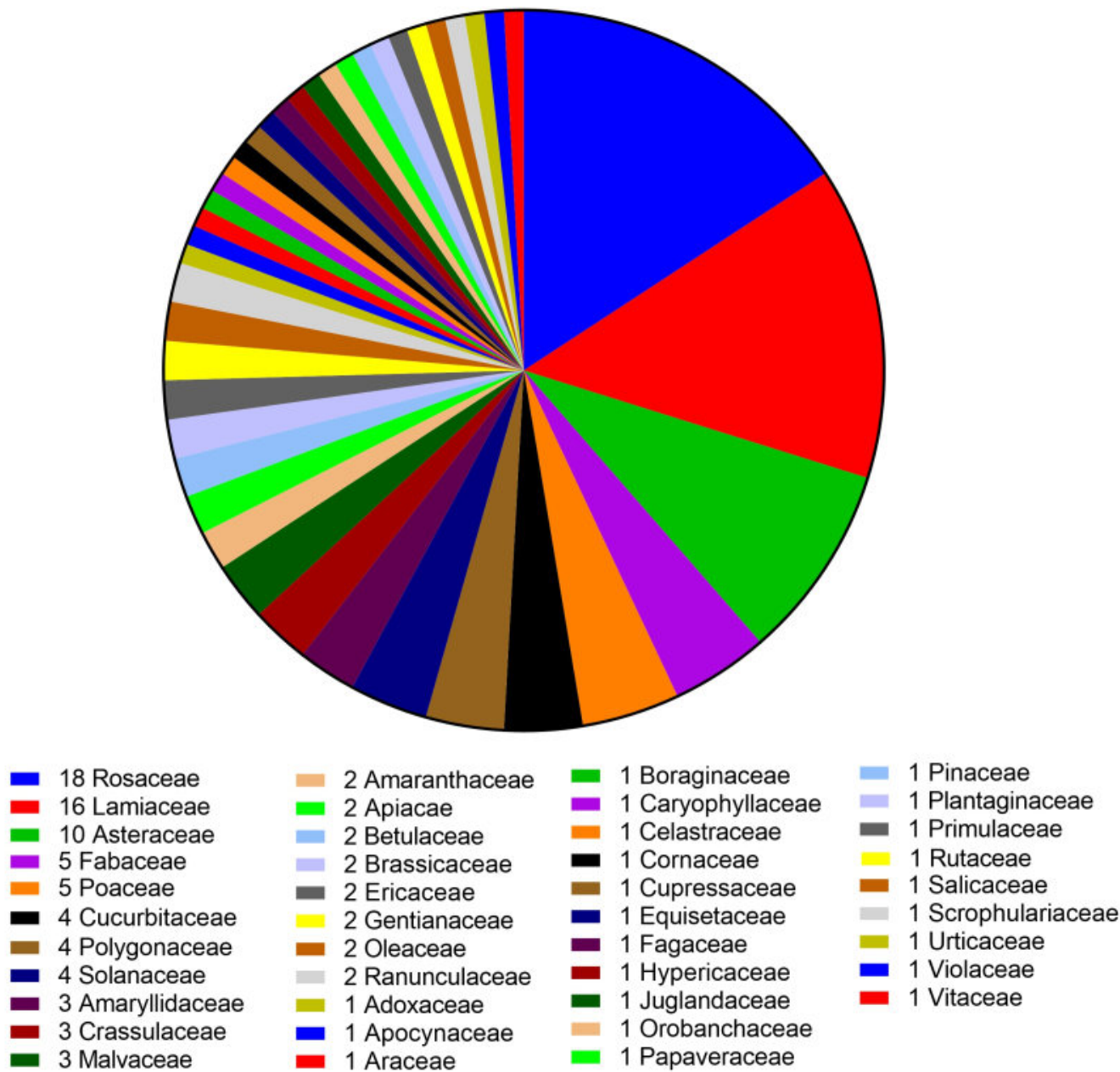

Figure 1. Number of plant families and their number of species, cited for ethnopharmacological applications, ranging from health food to various forms of medicine. 


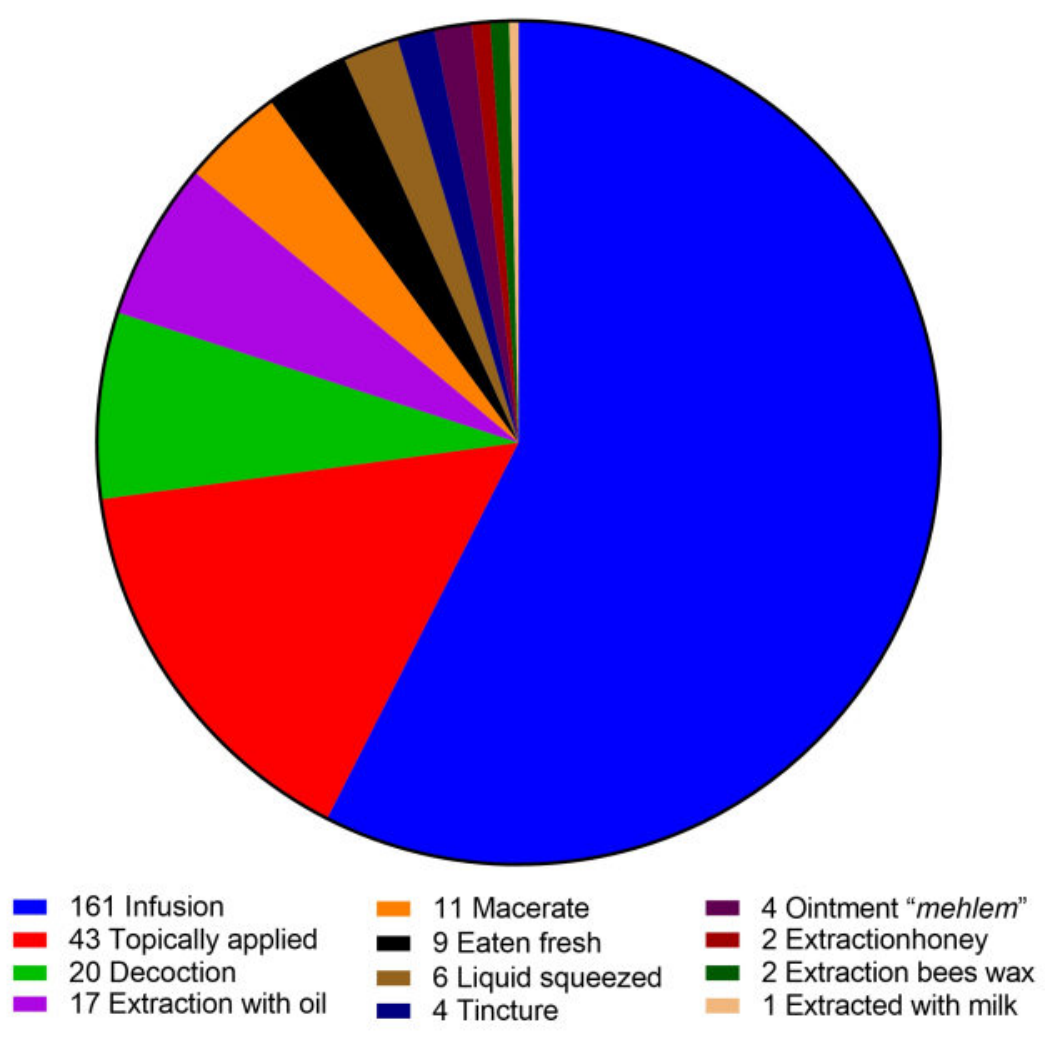

Figure 2. Preparation of plants for medicinal uses

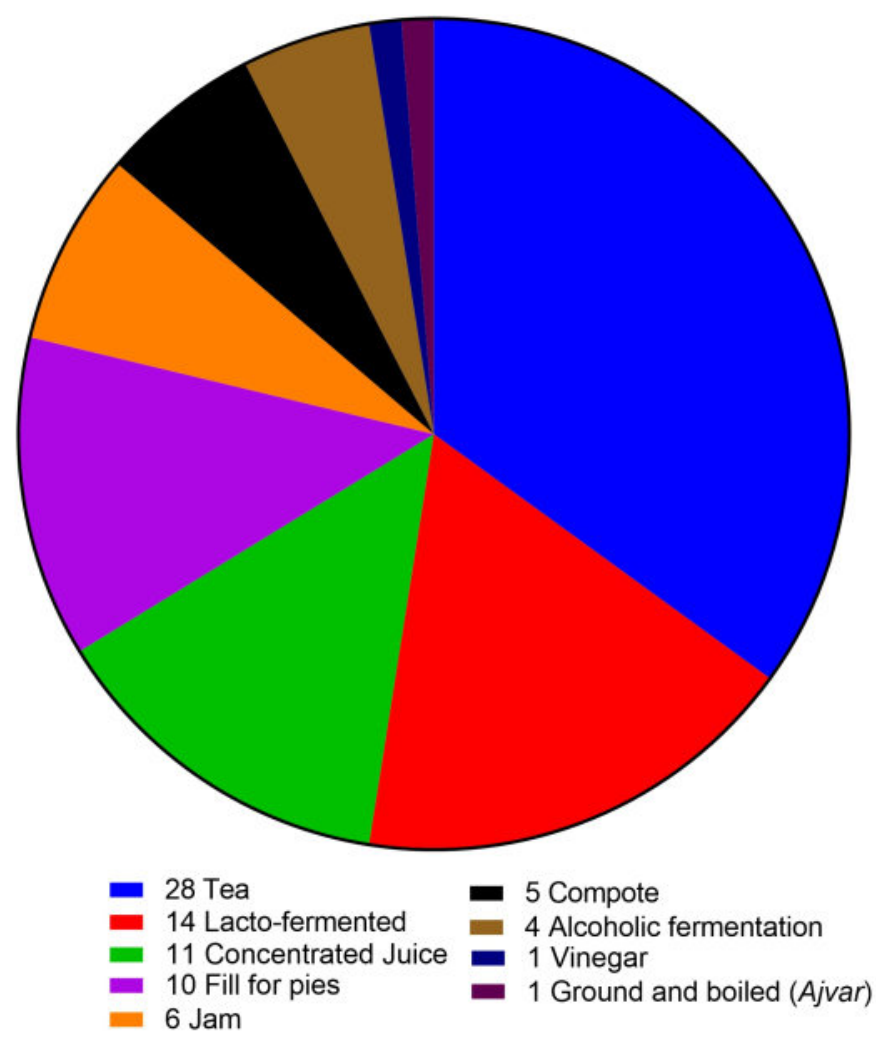

Figure 3. Preparation of plants for foods 


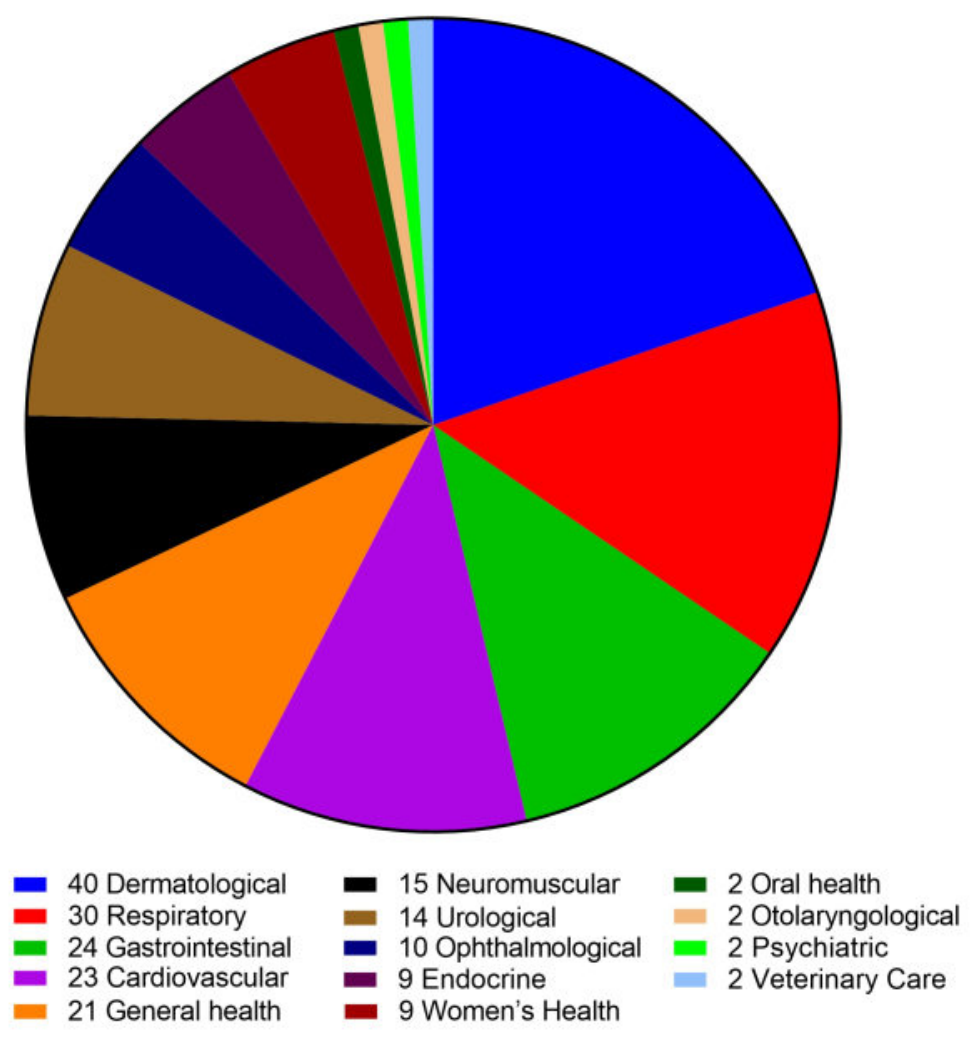

Figure 4. Medicinal uses of plant species

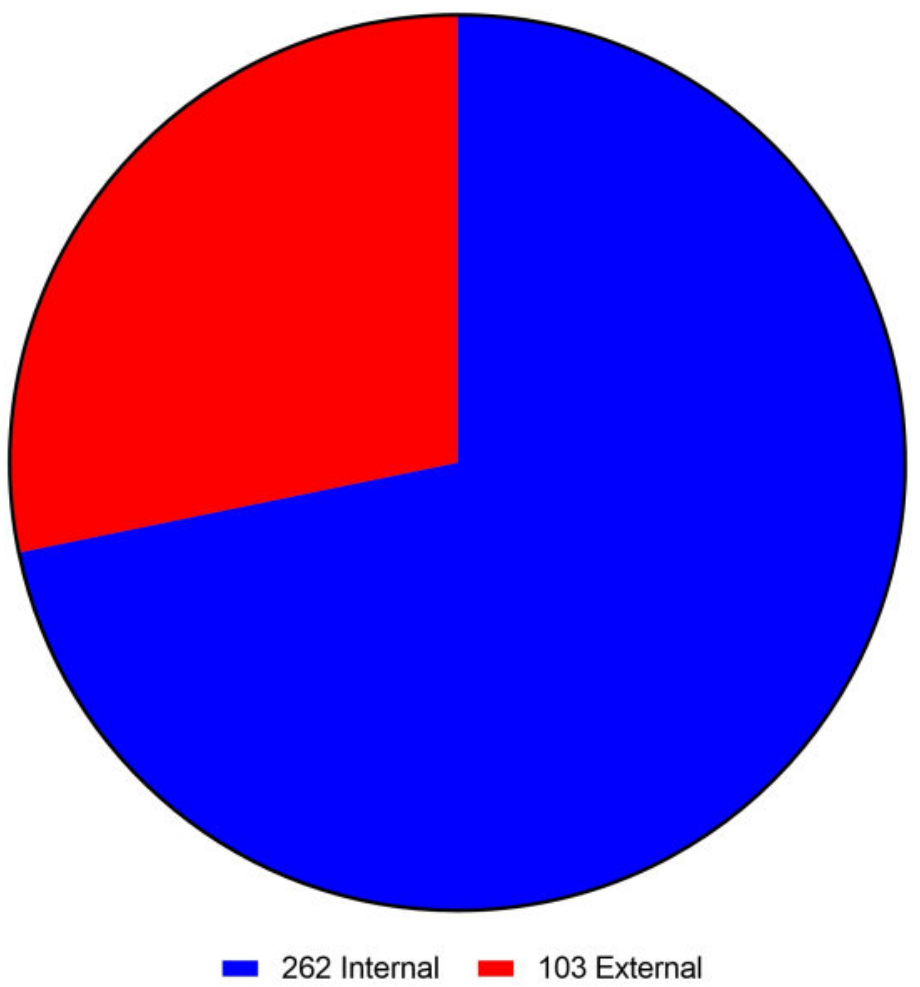

Figure 5. Administration of the extracts for medicinal purposes 


\section{Informants and Consensus}

There were a total of 1,050 use citations $\left(\mathrm{N}_{\mathrm{uc}}\right)$, and taxa were cited for different categories 389 times $\left(\mathrm{N}_{\mathrm{t}}\right)$. Categories of use are described with examples in Table 1 . The number of taxa $\left(\mathrm{N}_{\mathrm{t}}\right)$, number of use citations $\left(\mathrm{N}_{\mathrm{uc}}\right)$ and the informants consensus factor $\left(F_{i c}\right)$ for each category is reported in Table 2.
The most frequently cited $\left(\mathrm{N}_{\mathrm{uc}}: 327\right)$ use of taxa was for dermatological applications, followed by food (255), gastrointestinal (88), respiratory (83), and cardiovascular (78). The highest consensus $\left(F_{\text {ic }} \geq 0.75\right)$ was for taxa used for oral health $\left(F_{i c}: 0.952\right)$, dermatological (0.880), otolaryngological (0.857), food (0.756) and psychiatric (0.750) applications.

Table 2. Informant consensus

\begin{tabular}{l|c|c|c|c}
\hline $\begin{array}{c}\text { Category of Local } \\
\text { Use }\end{array}$ & $\begin{array}{c}\text { Number of Taxa } \\
\left(N_{t}\right)\end{array}$ & $\begin{array}{c}\text { Number of } \\
\text { Distinct Reports }\end{array}$ & $\begin{array}{c}\text { Number of Use } \\
\text { Citations }\left(N_{u c}\right)\end{array}$ & $\begin{array}{c}\text { Informant's } \\
\text { Consensus } \\
\text { Factor }\left(F_{i c}\right)\end{array}$ \\
\hline Cardiovascular & 23 & 33 & 78 & 0.714 \\
\hline Dermatological & 40 & 81 & 327 & 0.880 \\
\hline Endocrine & 9 & 12 & 21 & 0.600 \\
\hline Food & 63 & 102 & 255 & 0.756 \\
\hline Gastrointestinal & 24 & 30 & 88 & 0.736 \\
\hline General health & 21 & 25 & 55 & 0.630 \\
\hline Neuromuscular & 15 & 18 & 35 & 0.588 \\
\hline Ophthalmological & 10 & 12 & 22 & 0.571 \\
\hline Oral health & 2 & 3 & 22 & 0.952 \\
\hline Otolaryngological & 2 & 3 & 8 & 0.857 \\
\hline Psychiatric & 2 & 3 & 5 & 0.750 \\
\hline Respiratory & 30 & 41 & 83 & 0.646 \\
\hline Urological & 14 & 14 & 30 & 0.552 \\
\hline Women's Health & 9 & 10 & 17 & 0.500 \\
\hline Veterinary Care & 2 & 2 & 4 & 0.667 \\
\hline Overall Total & 266 & 389 & 1050 & \\
\hline
\end{tabular}

Legend: Informant consensus concerning the internal use of local plants and fungi.

\section{Use-Value for Cited Taxa}

A detailed report of $U_{\mathrm{c}}$ values for all cited taxa is provided in Appendix I. The average $U_{\mathrm{c}}$ was 0.095 . $\mathrm{H}$. perforatum had the highest use-value index score of all species reported $\left(U V_{c}: 2.56\right)$. Ten species had a use-value index score greater than 0.25 , and all were collected from the wild: Achillea millefolium, Matricaria recutita, Vaccinium myrtillus, Gentiana lutea, Hypericum perforatum, Origanum vulgare, Thymus serpyllum, Plantago major, Rosa canina, and Urtica dioica. Notably, most species were cited for a number of applications. For example, while all reports of $T$. serpyllum were for its preparation as an infusion of aerial parts, the infusion was cited a variety of uses, ranging from food, general health promotion, and for various medical applications for women's health, neuromuscular, respiratory, and urological complaints. Likewise, U. dioica was reported to be prepared as an infusion (of the aerial parts, seeds, or flowers) for food (as a tea beverage) and for various medicinal applications ranging from urological, general health, cardiovascular, neuromuscular or 
endocrine system complaints (Appendix I).

\section{Reports of Animal, Mineral and Industrial Products}

In addition to plant and fungal ingredients, reports of animal, mineral and industrial ingredients for medicinal applications were also recorded. Thirteen animal species were cited, with 38 distinct uses reported, and a total of 58 individual use citations (Appendix II). Of these, the top use-value index scores were for sheep products $\left(\mathrm{N}_{\mathrm{uc}}: 0.132\right)$, with different dermatological applications cited using milk, gallbladder, skin, fat or feces; and human products $\left(\mathrm{N}_{\mathrm{uc}}: 0.088\right)$ of urine and breast milk used for otolaryngological and dermatological applications.

Fourteen ingredients of mineral or industrial origin were cited for 17 distinct uses reported and 21 total citations for dermatological, veterinary and ophthalmological applications (Appendix III). The top two reported ingredients had low use value scores (relative to plant or animal ingredients); both ash and sugar had as UV of 0.033 .

\section{DISCUSSION}

\section{Similarities with other Reports in the Balkan Literature}

Similar to a number of previous studies conducted in different communities spread across the Western Balkans (including Albania, Kosovo, Serbia and Montenegro), the most frequently cited plant families for food and medicinal use were Rosaceae, Lamiaceae and Asteraceae. Their predominance as a source of wild food and medicine is thus well documented throughout the region and not surprising to find here as well.
Measure of use-value indices for individual taxa can be especially useful for cross-cultural comparison studies concerning the use of different taxa, and mechanisms for data analysis between two or three groups have been explored with field data collected in this region of the Balkans. Due to limitations in the present study design (uneven numbers from different ethnicities having been recruited), a rigorous cross-cultural assessment of use-values across ethnic groups was not possible here. However, comparison of the present study data with that of a previous study conducted in SW Kosovo revealed that six of the eight most commonly cited taxa (with $>30 \%$ of respondents citing their use) were also reported to have the highest $\mathrm{UV}_{\mathrm{c}}$ scores $(>0.25)$ here: Achillea millefolium, Urtica dioica, Hypericum perforatum, Thymus serpyllum, Matricaria recutita and Vaccinium myrtillus. The other two high ranking taxa from the prior study were also documented in the present work, but at a lower frequency: Sambucus nigra L. (UV: 0.176$)$ and Tilia platyphyllos Scop. (UVc: 0.055). Furthermore, comparison of our data with the entire Western Balkan ethnobotanical literature available in English (see references cited in the introduction) revealed that the folk plant remedies with the highest fidelity levels, defined as those with high reports of the same specific use, were also recorded as being commonly used in the most of the considered studies.

Furthermore, in addition to their role in traditional medicine of this region, a number of these species have also been incorporated into the broader European market as plant food supplements, sold in various forms ranging from capsules, raw herbs, and tinctures; this includes $A$. millefolium, $H$. perforatum, $M$. recutita, $S$. nigra, T. serpyllum, $T$. platyphyllos, $U$. 
dioica, and V. myrtillus.

\section{Health Foods}

Most of the plant foods quoted as being "healthy" by the informants referred to a few wild vegetables used as filling for börek and to lacto-fermented cultivated vegetables. The Ottoman culinary tradition of preparing wild plant-based savoury pies is widespread across the Balkans and wild sorrel and dock leaves (Rumex spp.) represent the most used ingredients. Both plants - sour and astringent at the same time (sorrel more sour, dock more astringent) are consumed in the spring as a panacea and a healthy food serving as a reconstituent following the long, cold winter period. Moreover, similarly to what we found also among Albanian Gorani , the customs of preparing home-made lactofermented plant ingredients, to consume them during the winter, and also to drink the resulting sour liquid portion as a panacea is a cultural trait of South Slavs (and especially Gorani) and should be better investigated in terms of biological evaluation of the nutraceutical potentialities of these probiotic foods.

\section{Uncommon Plant Uses}

The most uncommon use documented in the present work concerned the use of Euonymus europaeus L. fruiting branches in teas as a cardiotonic. This is unusual because across Europe, the plant is considered toxic and has never been quoted in our prior field studies as being internally used. Although it was only reported by two informants, it was also being sold at a local market; this finding should be better investigated by assessment of the chemical makeup of the water infusion as it pertains to the plant's toxicological relevance as well as its phytopharmacology.

Vinca minor L. was another uncommonly recorded species used as infusion to improve the general health. In general, it is known to be a valuable medicinal plant use to prevention and treatment the cerebrovascular insufficiencies and disorders, it increases cerebral blood flow, oxygen consumption and glucose utilization. Further work on the bioactivity and toxicology of the traditional leaf infusion could be worthwhile.

\section{Other ingredients for local health practices}

In addition to medicinal plants, other ingredients gleaned from the environment are commonly used in the traditional medical practices of this region. For example, we documented the use of thirteen animal species for pharmacological application. This practice of using animal and their byproducts for medicine is known as zootherapy, and has constituted an important component of the pharmacopoeia across many cultures since ancient times. Similar to other contemporary studies on zootherapeutic practices, we identified insects, birds, mammals (small and large), and reptiles as ingredients for various medical afflictions. Unlike other studies on this topic, no aquatic animals were reported. It should be noted, however, that as this was not a primary line of inquiry in interviews, which were mainly focused on the ethnopharmacological uses of plants and fungi, the scope of animals uses and number of actual user reports are likely highly underreported in the present study. Further research into zootherapeutic practices, as well as other practices which incorporate industrial materials or minerals, would be useful to improving our understanding of this phenomenon in the 
Balkans.

\section{Traditional formulations Hypericum perforatum}

Of all of the species encountered in our field study, $H$. perforatum (locally referred to as kantarion) dominated the discussion of more than half $(52 \%)$ of all interviews conducted. It had the highest use-value index $\left(U V_{c}:\right.$ 2.56), much higher than the overall average of 0.095 . This is similar to results of an ethnobotanical study in Eastern Serbia, which also documented this as the most frequently cited species, with $40.5 \%$ of informants citing its use .

Here, the flowering aerial parts were reported to prepared by infusion to be drunk for urological, respiratory and gastrointestinal complaints; but the most common preparation involved macerating the flowering aerial parts in a clear bottle full of olive or sunflower oil in the sunlight for a period of 40 days, at which time the oil will take on a deep blood red color. In some cases, this recipe included modifications, such as the addition of Calendula officinalis flowers to the oil macerate, or addition of other materials such as iodine or brick powder to the final oil product. The $H$. perforatum flower oil preparation (Oleum Hyperici), was reported for many different topical applications for dermatological, cardiovascular and veterinary use. Almost half $(44 \%)$ of all informants referenced specific dermatological applications of Oleum Hyperici for wound healing, burn injuries, skin infections, eczema, and skin softening (emollient).

The antibacterial properties of $H$. perforatum is well known; growth inhibitory action of its extracts against $S$. aureus have been previously reported. A major constituent responsible for the antibacterial activity of extracts from this species is the phloroglucinol, hyperforin. However, this compound is very unstable, especially in the presence of heat and light, calling into question whether or not it is present in the traditional oil, and if not, what is responsible for the purported antibacterial activity of the folk remedy.

Another major constituent commonly found in $H$. perforatum extracts is the napthodianthrone, hypericin. It is known to be a major cause of photosensitization and cause of hypericism, a form of photodermatitis. Research on the topical application of hypericin gel and oil formulations demonstrated a clinically relevant rise in skin erythema. However, in our extensive discussions with informants on the use and effects (including adverse effects) of topical use of the kantarion oil, there were no reports of photodermatitis or a need to avoid sun exposure during use. This suggested that hypericin might be lacking in the traditional formulation, and this was confirmed in biochemical analyses .

\section{CONCLUSIONS}

A total of 389 distinct ethnomedical and food uses of 115 plant, 4 fungal, and 13 animal species were cited. Interviews with 91 informants yielded 1,050 total use citations for plants and fungi, and an additional 58 for animal products, with the highest consensus rankings attributed to the categories of oral health, dermatological, otolaryngological, food, and psychiatric applications.

In comparison to other ethnobotanical studies conducted in the Western Balkans, our findings reaffirm the importance of certain families (Rosaceae, Lamiaceae and Asteraceae) as sources of food and medicine in this region of South Kosovo. Of 
note, a total of 21 species are used for the purpose of general health, and many of these are commonly consumed as a "health food". We noted two unusual plant uses not previously documented in the Balkans: the use of Vinca minor leaf infusion as a healthy beverage and an infusion of Euonymus europaeus as a cardiotonic. We also noted the critical importance of Hypericum perforatum as an ingredient for infusion and oil formulations used for several different categories of medical care, with dermatological application of the Oleum Hyperici being the most prevalent of all plant uses recorded in the region.

The $H$. perforatum oleolite paradox highlights an important issue in ethnopharmacology. Laboratory produced extracts do not necessarily reflect the chemical composition of the traditional medicine in use by people. Differences in extraction method and formulation or delivery vehicle can yield substantial differences in the final product's chemical makeup and bioavailability, and thus impact its potential bioactivity and toxicity. In order to gain a more accurate understanding of the potential efficacy and safety of traditional medicines in the future, it is imperative that precise details concerning the extraction and formulation of raw natural materials are recorded and reported.

In conclusion, this study provides a solid foundation for the understanding of ethnomedical practices of communities in South Kosovo. Our findings demonstrate that local people rely on a broad and biodiverse set of natural resources for their food and health. Furthermore, natural resources of this region provide an important source for acquisition of key ingredients for food and medicine by local people. Ethnobiological research can provide critical insight into how local people interact with the natural world, and provide baseline data for future pharmacological studies on traditional remedies. In particular, details concerning the parts used, mode of preparation or formulation, disease target, mode of application, frequency of use, and adverse effects can provide important clues for consideration in future laboratory analyses of the cited ingredients for potential toxicity and bioactivity.

\section{ACKNOWLEDGEMENTS}

We would like to extend our heartfelt thanks to the communities and people who agreed to participate in this study. Special thanks to the students who participated in the training workshop and assisted with interviews: Bledar Pulaj, Fatbardhë Kurti, Fisnik Asllani, Pajtim Bytyqi, Ylberza Thaqi, Mirsad Mehmeti, Andonita Buçinca, Leonora Ibrahimi, Arbnora Bytyqi, Florentina Zeneli, Zuhid Rama, and Samir Toro. Funding support for this study was provided by the US State Department, US Embassy in Kosovo (grant number S-KV420-14GR-096).

\section{REFERENCES}

Alves RRN and Rosa IL (2006). Why study the use of animal products in traditional medicines? Journal of Ethnobiology and Ethnomedicine 1:5.

Alves RRN and Alves HN (2011). The faunal drugstore: Animal-based remedies used in traditional medicines in Latin America. Journal of Ethnobiology and Ethnomedicine 7:9-9.

Blumenthal M, Ed. (1998). The Complete German Commission E Monographs. Boston, American Botanical Council in Cooperation with Integrative Medicine Communications.

Costa-Neto $E$ (1999). Healing with animals in Feira de Santana City, Bahia, Brazil. Journal of Ethnopharmacology 65(3):225 - 230.

de Albuquerque UP, de Medeiros PM, de Almeida ALS, Monteiro JM, de Freitas Lins Neto EM, de 
Melo JG and dos Santos JP (2007). Medicinal plants of the caatinga (semi-arid) vegetation of NE Brazil: A quantitative approach. Journal of Ethnopharmacology 114(3):325-354.

Demiri M (1981). Flora ekskursioniste e Shqipërisë. Tirana, Libri Shkollor.

EI-Deir ACA, Collier CA, de Almeida Neto MS, Silva KMdS, Policarpo IdS, Araújo TAS, Alves RRN, de Albuquerque UP and de Moura GJB (2012). Ichthyofauna used in traditional medicine in Brazil. Evidence-based Complementary and Alternative Medicine : eCAM 2012:474716.

Fischhof P, Möslinger-Gehmayr R, Herrmann W, Friedmann A and Russmann D (1996). Therapeutic efficacy of vincamine in dementia. Neuropsychobiology 34(1):29-35.

Garcia-Alvarez A, Egan B, de Klein S, Dima L, Maggi $F M$, Isoniemi M, Ribas-Barba L, Raats MM, Meissner EM, Badea M, Bruno F, Salmenhaara $M$, Milà-Villarroel $R$, Knaze $V$, Hodgkins C, Marculescu A, Uusitalo L, Restani P and Serra-Majem L (2014). Usage of plant food supplements across six European countries: Findings from the PlantLIBRA consumer survey. PLOS ONE 9(3):e92265.

Gibbons S. OB, Johnsen, I. (2002). The genus Hypericum - a valuable resource of antistaphylococcal leads. Fitoterapia 73:300-304.

Heinrich M, Ankli A, Frei B, Weimann C and Sticher O (1998). Medicinal plants in Mexico: healers' consensus and cultural importance. Social Science \& Medicine 47(11):1859-1871.

ISE. (2006). "International Society of Ethnobiology Code of Ethics (with 2008 additions)." from http://ise.arts.ubc.ca/global_coalition/ethics.php.

Jarić S, Mačukanović-Jocić M, Djurdjević L, Mitrović M, Kostić O, Karadžić $B$ and Pavlović $P$ (2015). An ethnobotanical survey of traditionally used plants on Suva planina mountain (south-eastern Serbia). Journal of Ethnopharmacology 175:93-108.

Jarić S, Mitrović M and Pavlović P (2014). An ethnobotanical and ethnomedical study on the use of wild medicinal plants in rural areas of Serbia. Ethnobotany and Biocultural Diversities in the Balkans. A. Pieroni and C. L. Quave. New York, Springer: 87-112.

Jarić S, Popović Z, Mačukanović-Jocić M, Djurdjević L, Mijatović M and Karadžić B (2007).
An ethnobotanical study on the usage of wild medicinal herbs from Kopaonik Mountain (Central Serbia). Journal of Ethnopharmacology 111.

Jordanov D (1963-1979). Flora NR Bulgaria. Sofia, BANU.

Lev E (2003). Traditional healing with animals (zootherapy): medieval to present-day Levantine practice. Journal of Ethnopharmacology 85(1):107 - 118.

Łuczaj Ł, Fressel N and Perković S (2013). Wild food plants used in the villages of the Lake Vrana Nature Park (northern Dalmatia, Croatia). Acta Societas Botanicorum Poloniae 82.

Lyles JT, Kim A, Nelson K, Bullard-Roberts AL, Hajdari A, Mustafa B and Quave CL (2017). The Chemical and Antibacterial Evaluation of St. John's Wort Oil Macerates Used in Kosovar Traditional Medicine. Frontiers in Microbiology 8(1639).

Menković N, Šavikin K, Tasić S, Zdunić G, Stešević D and Milosavljević S (2011). Ethnobotanical study on traditional uses of wild medicinal plants in Prokletije Mountains (Montenegro). Journal of Ethnopharmacology 133.

Mustafa B, Hajdari A, Krasniqi F, Hoxha E, Ademi $\mathrm{H}$ and Quave CL (2012). Medical ethnobotany of the Albanian Alps in Kosovo. Journal of Ethnobiology and Ethnomedicine 8.

Mustafa B, Hajdari A, Pajazita Q, Syla B, Quave $C L$ and Pieroni A (2011). An ethnobotanical survey of the Gollak region, Kosovo. Genetic Resoures and Crop Evolution 59.

Mustafa B, Hajdari A, Pieroni A, Pulaj B, Koro X and Quave CL (2015). A cross-cultural comparison of folk plant uses among Albanians, Bosniaks, Gorani and Turks living in south Kosovo. Journal of Ethnobiology and Ethnomedicine 11(1):39.

MycoBank. (2016). "MycoBank Database: Fungal databases, nomenclature and species banks." Retrieved June 12016.

Pajazitaj Q (2004). Përcaktuesi i bimëve Pteridofite dhe Spermatofite. Prishtina, Universiteti i Prishtinës.

Paparisto K, Vangjeli J, Ruci B, Mullaj A and Qosja X (1988-2000). Flora e Shqipërisë. 
Tirana, ASHASH, Instituti i Kërkimeve Biologjike.

Pieroni A (2008). Local plant resources in the ethnobotany of Theth, a village in the Northern Albanian Alps. Genetic Resoures and Crop Evolution 55.

Pieroni A (2010). People and plants in Lëpushë. Traditional medicine, local foods, and postcommunism in a North Albanian village. Ethnobotany in the new Europe: People, Health and Wild Plant Resources. M. PardodeSantayana, A. Pieroni and R. Puri. New York/Oxford, Berghahn.

Pieroni A, Cianfaglione K, Nedelcheva A, Hajdari A, Mustafa B and Quave CL (2014). Resilience at the border: traditional botanical knowledge among Macedonians and Albanians living in Gollobordo, Eastern Albania. Journal of Ethnobiology and Ethnomedicine 10(1):1-31.

Pieroni A, Dibra B, Grishaj G, Grishaj I and Maçai SG (2005). Traditional phytotherapy of the Albanians of Lepushe, Northern Albanian Alps. Fitoterapia 76.

Pieroni A, Elena Giusti M, Münz H, Lenzarini C, Turković G and Turković A (2003). Ethnobotanical knowledge of the IstroRomanians of Žejane in Croatia. Fitoterapia 74(7-8):710-719.

Pieroni A, Giusti ME and Quave CL (2011). Cross-cultural ethnobiology in the Western Balkans: Medical ethnobotany and ethnozoology among Albanians and Serbs in the Pešter Plateau, Sandžak, South-Western Serbia. Human Ecology 39.

Pieroni A and Quave CL, Eds. (2014). Ethnobotany and Biocultural Diversities in the Balkans. New York, NY, Springer Press.

Pieroni A, Rexhepi B, Nedelcheva A, Mustafa B, Hajdari A, Kolosova V, Cianfaglione K and Quave CL (2013). One century later: the folk botanical knowledge of the last remaining Albanians of the upper Reka Valley, Mount Korab, Western Macedonia. Journal of Ethnobiology and Ethnomedicine 9.

Quave CL and Pieroni A (2014). Fermented foods for food security and food sovereignty in the Balkans: A case study of the Gorani people of Northeastern Albania. Journal of Ethnobiology 34.

Quave CL and Pieroni A (2015). A reservoir of ethnobotanical knowledge informs resilient food security and health strategies in the Balkans. Nature Plants 1:14021.

Redžić S (2006). Wild edible plants and their traditional use in the human nutrition in Bosnia and Herzegovina. Ecology of Food and Nutrition 45.

Redžić S (2007). The ecological approach to ethnobotany and ethnopharmacology of population in Bosnia and Herzegovina. Collegium Antropologicum 31.

Rexhepi B, Mustafa B, Hajdari A, RushidiRexhepi J, Quave CL and Pieroni A (2013). Traditional medicinal plant knowledge among Albanians, Macedonians and Gorani in the Sharr Mountains (Republic of Macedonia). Genetic Resoures and Crop Evolution 60.

Saddiqe Z, Naeem I and Maimoona A (2010). A review of the antibacterial activity of Hypericum perforatum L. Journal of Ethnopharmacology 131(3):511-521.

Šarić-Kundalić B, Dobeš C, Klatte-Asselmeyer V and Saukel J (2010). Ethnobotanical study on medicinal use of wild and cultivated plants in middle, south and west Bosnia and Herzegovina. Journal of Ethnopharmacology 131(1):33-55.

Šarić-Kundalić B, Fritz E, Dobeš C and Saukel J (2010). Traditional Medicine in the Pristine Village of Prokoško Lake on Vranica Mountain, Bosnia and Herzegovina Scientia Pharmaceutica 78:275-290.

Šavikin K, Zdunic G, Menkovic N, Zivkovic J, Cujic N and Terescenko M (2013). Ethnobotanical study on traditional use of medicinal plants in South-Western Serbia, Zlatibor district. Journal of Ethnopharmacology 146.

Schempp CM, Pelz K, Wittmer A, Schöpf E and Simon JC (1999). Antibacterial activity of hyperforin from St John's wort, against multiresistant Staphylococcus aureus and gram-positive bacteria. The Lancet 353(9170):2129.

Schempp. C.M. LR, Winghofer B., Simon J.C. (2000). Effect of topical application of Hypericum perforatum extract (St. John's wort) on skin sensititivty to solar simulated radiation. Photodermatology Photoimmunology \& Photomedicine 16:125-128.

SERNEC. (2016). "Southeast Regional Network of Expertise and Collections." 
Stevanović ZD, Petrović M and Aćić S (2014). Ethnobotanical knowledge and traditional use of plants in Serbia in relation to sustainable development. Ethnobotany and Biocultural Diversities in the Balkans. A. Pieroni and C. L. Quave. New York, Springer: 229-252.

Stevens P. (2001 onwards). "Angiosperm Phylogeny Website." Version 13.

Tutin T, Heywood V, Burges $\mathrm{N}$, Valentine D, Walters S and Webb D (1964). Flora Europaea. Cambridge, UK, University Press.

Ulaj R, Sylejmani D and Gashi S (2015). Kosovo in Figures 2014, Series 1: General Statistics,
Statistical Office of Kosovo. 1.

Vallejo JR and González JA (2014). Fish-based remedies in Spanish ethnomedicine: a review from a historical perspective. Journal of Ethnobiology and Ethnomedicine 10:37-37.

Zlatković BK, Bogosavljević SS, Radivojević AR and Pavlović MA (2014). Traditional use of the native medicinal plant resource of Mt. Rtanj (Eastern Serbia): Ethnobotanical evaluation and comparison. Journal of Ethnopharmacology 151.

Received: 16 October 2017

Accepted: 20 February 2018

Published: 02 March 2018 


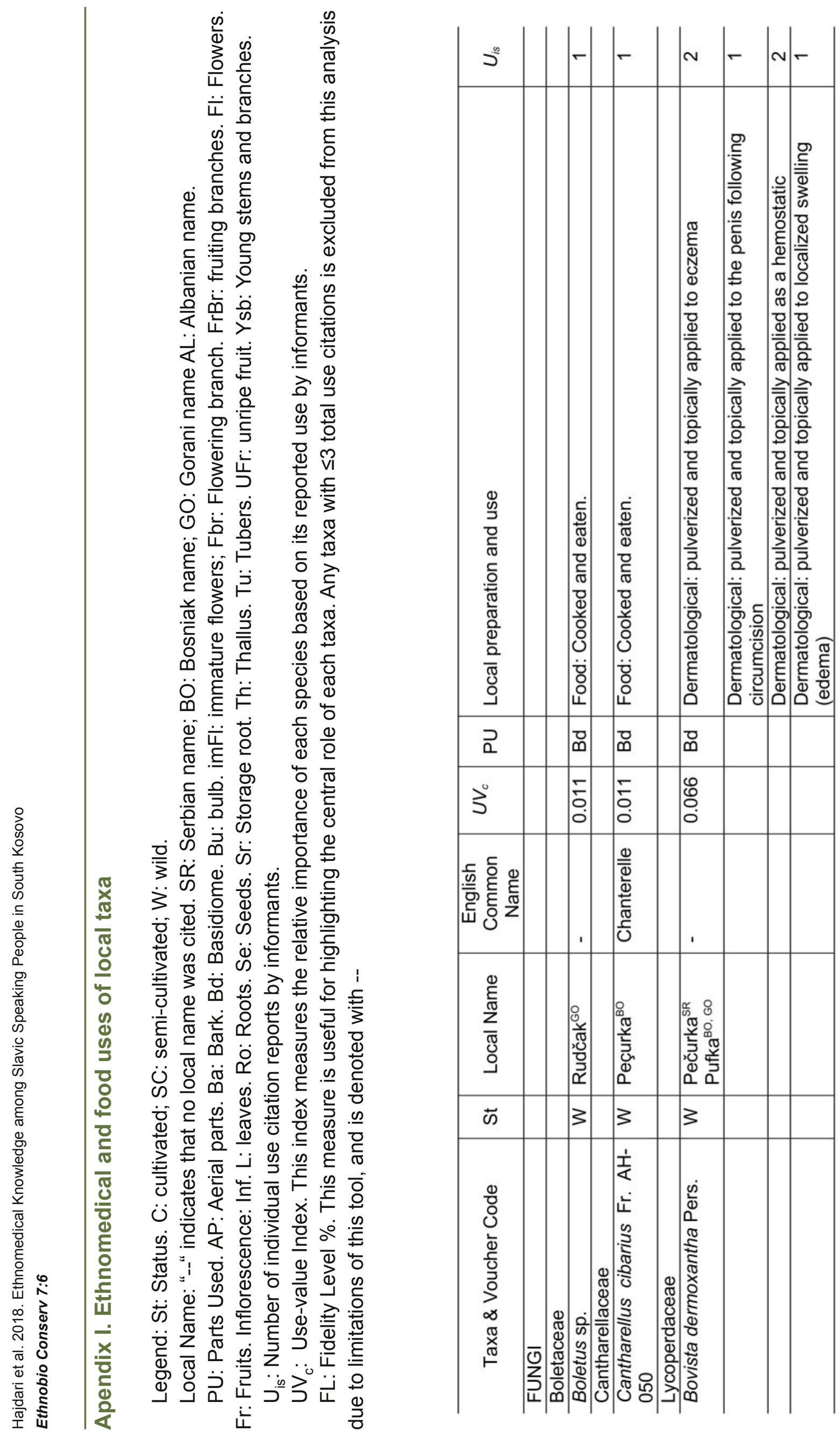




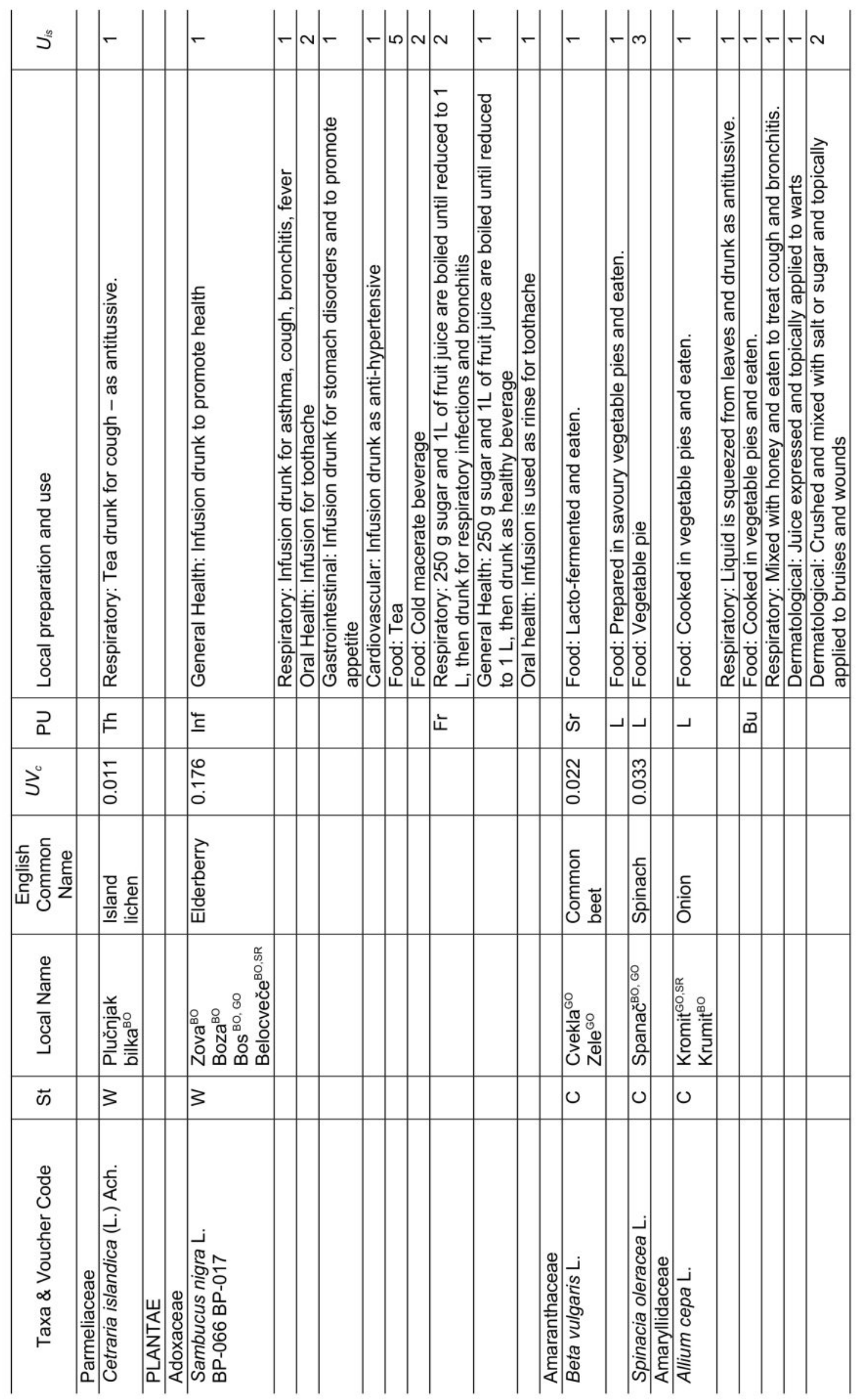




\begin{tabular}{|c|c|c|c|c|c|c|c|c|c|c|c|c|c|c|}
\hline $3^{5}$ & 0 & $r$ & - & $\sim$ & is & - & - & - & - & - & $\Lambda$ & m m N & $v|N|-$ & \\
\hline 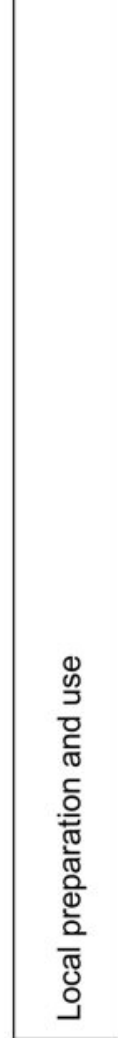 & 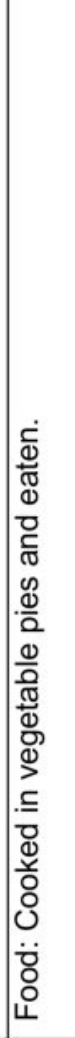 & 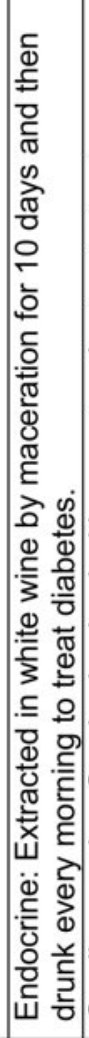 & 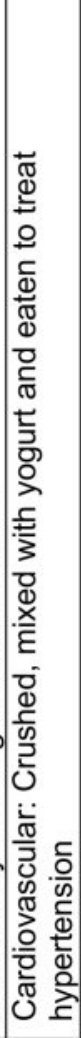 & 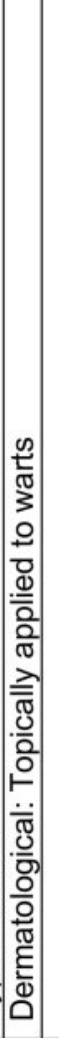 & 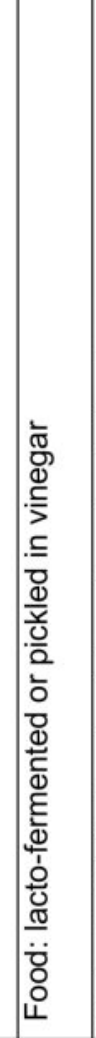 & 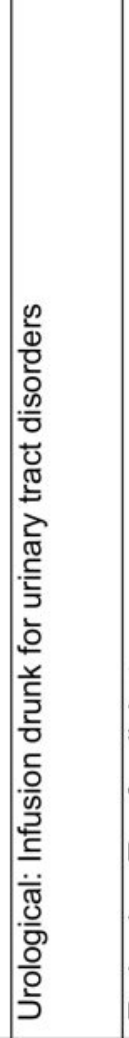 & 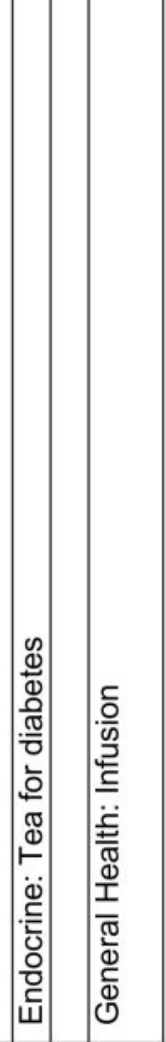 & 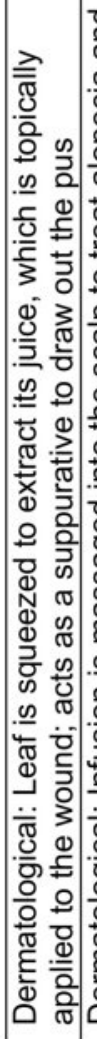 & 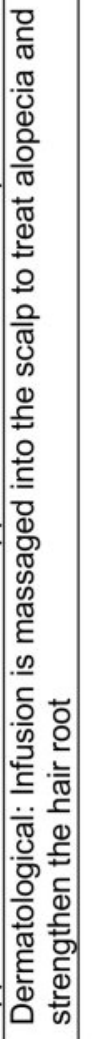 & 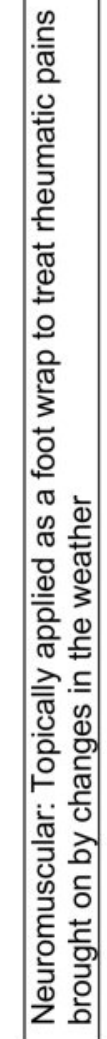 & 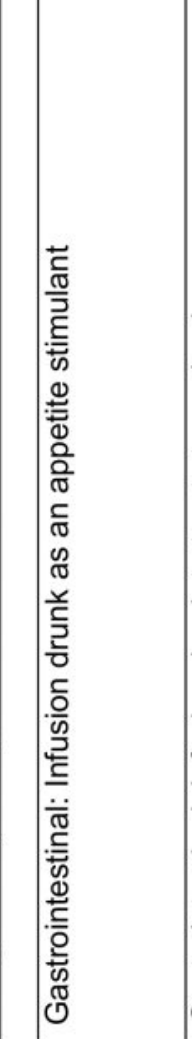 & 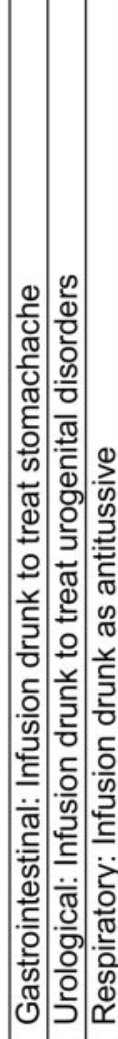 & 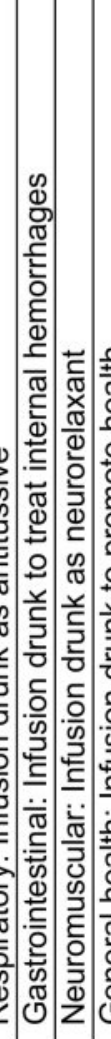 & \\
\hline$\stackrel{\supset}{\Omega}$ & 这 & & ฉె & & 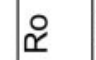 & 这 & ـ & & $\frac{0}{<}$ & 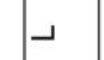 & $\frac{Q}{<}$ & & & \\
\hline $3^{\circ}$ & 令 & & ְֶׁ & & 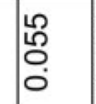 & ָָ & 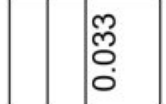 & & & $\underset{0}{\bar{\sigma}}$ & 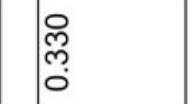 & & & \\
\hline 它 & 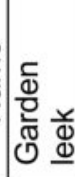 & & 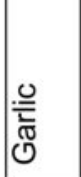 & & 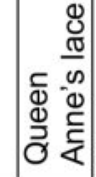 & 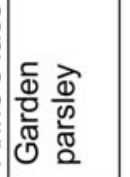 & 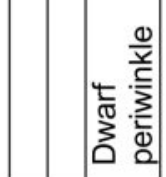 & & & ' & 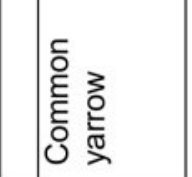 & & & \\
\hline 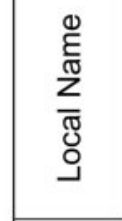 & 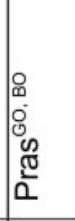 & & 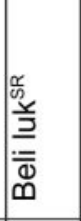 & & 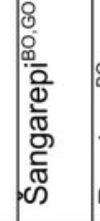 & 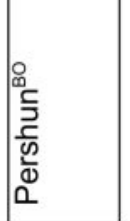 & 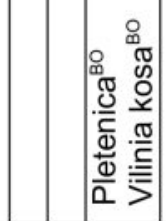 & & & 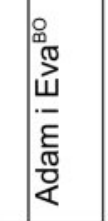 & 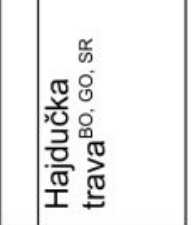 & & & \\
\hline ळ & 0 & & 0 & & 0 & 0 & 0 & & & 3 & 3 & & & \\
\hline 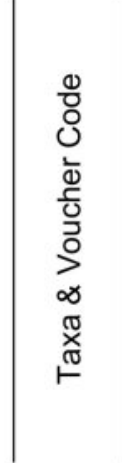 & 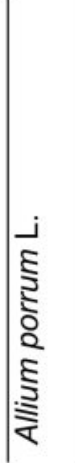 & & 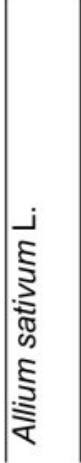 & & 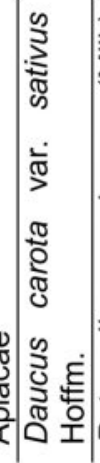 & 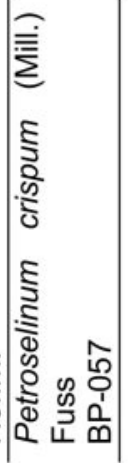 & 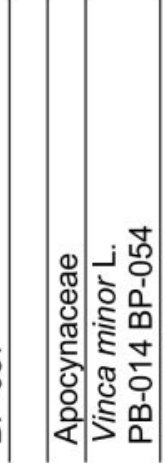 & & & 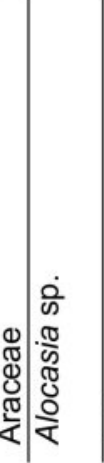 & 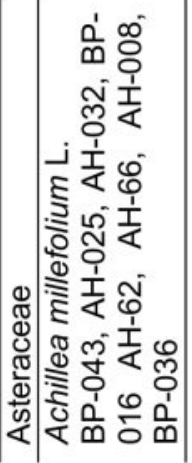 & & & \\
\hline
\end{tabular}




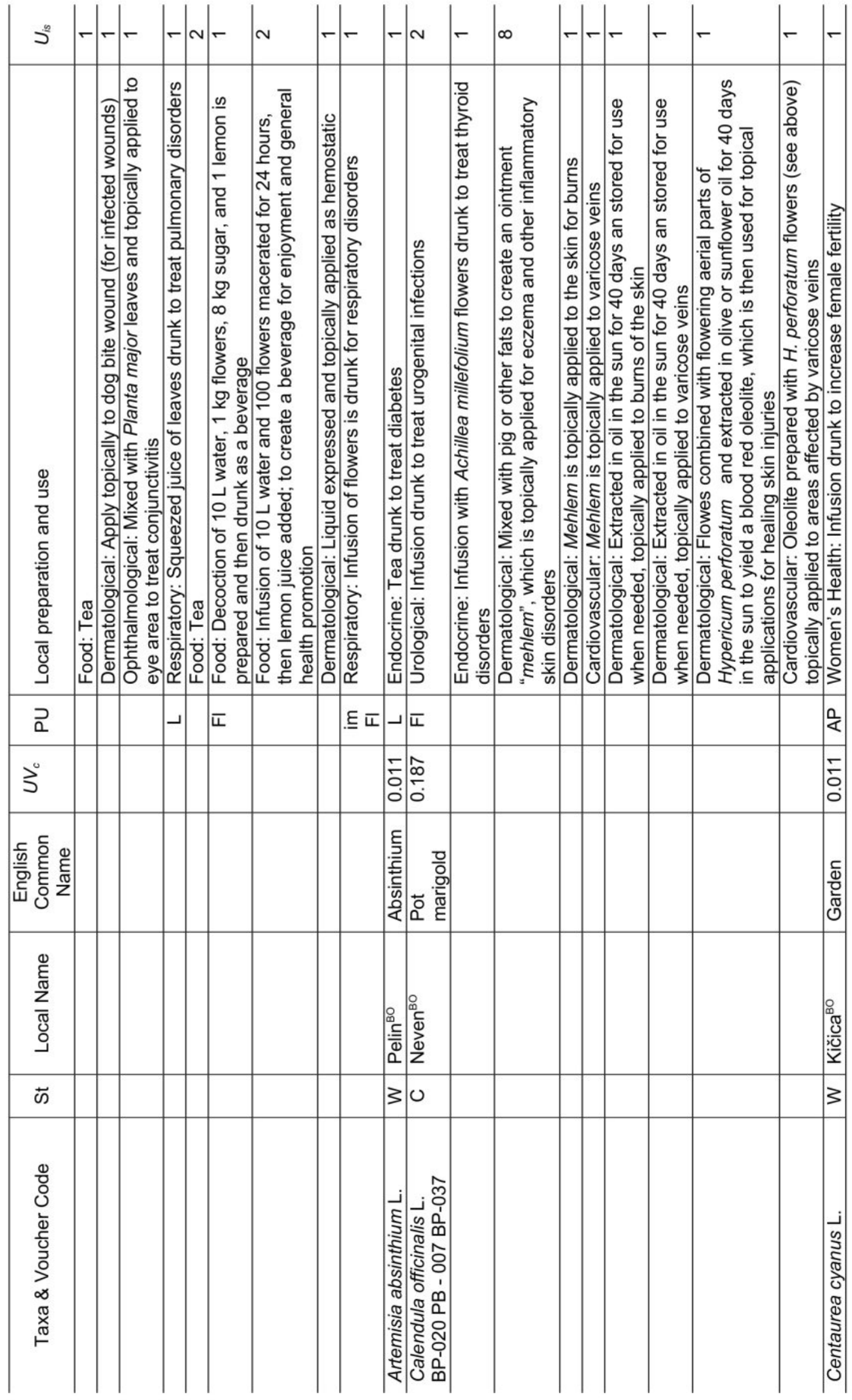




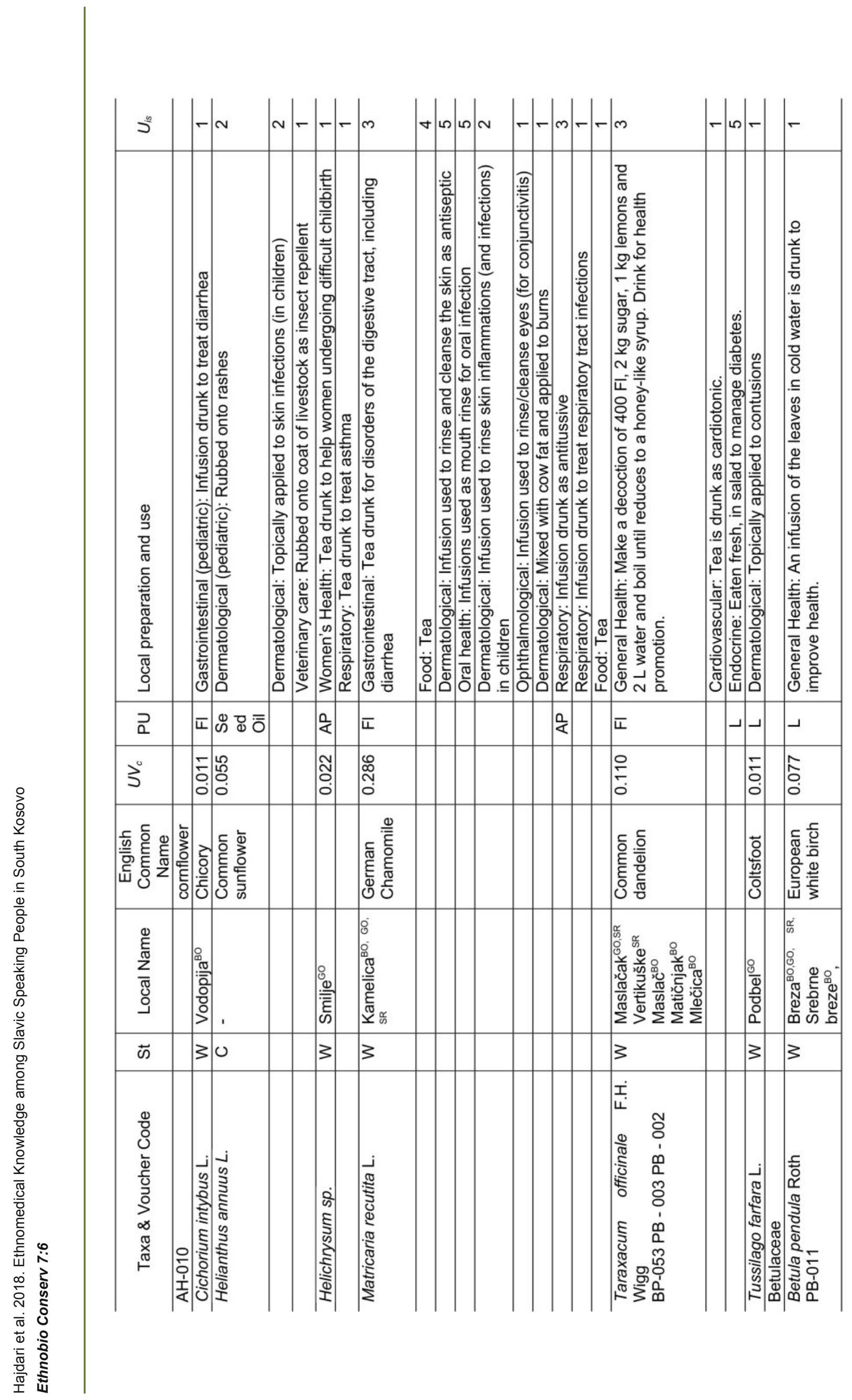




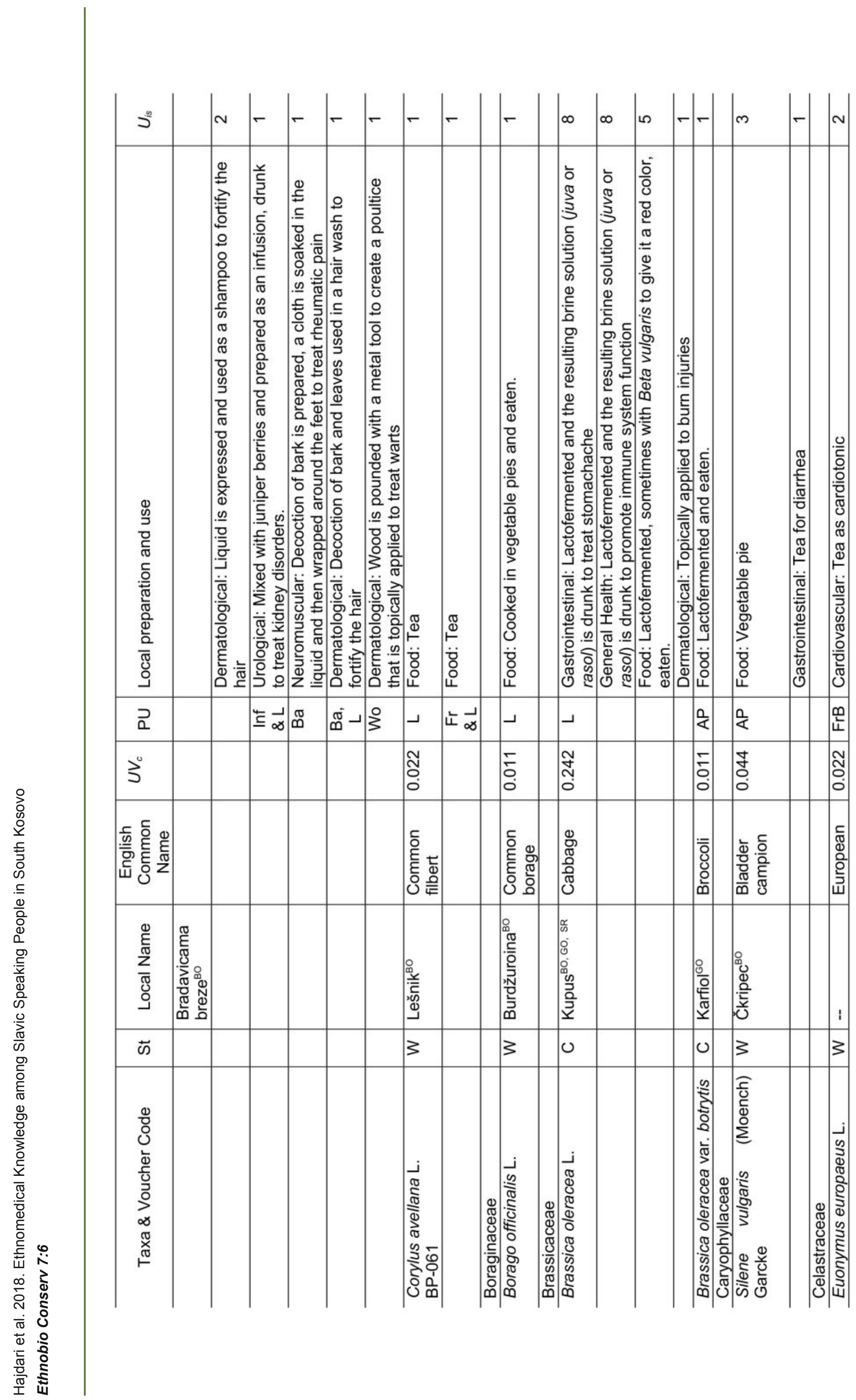




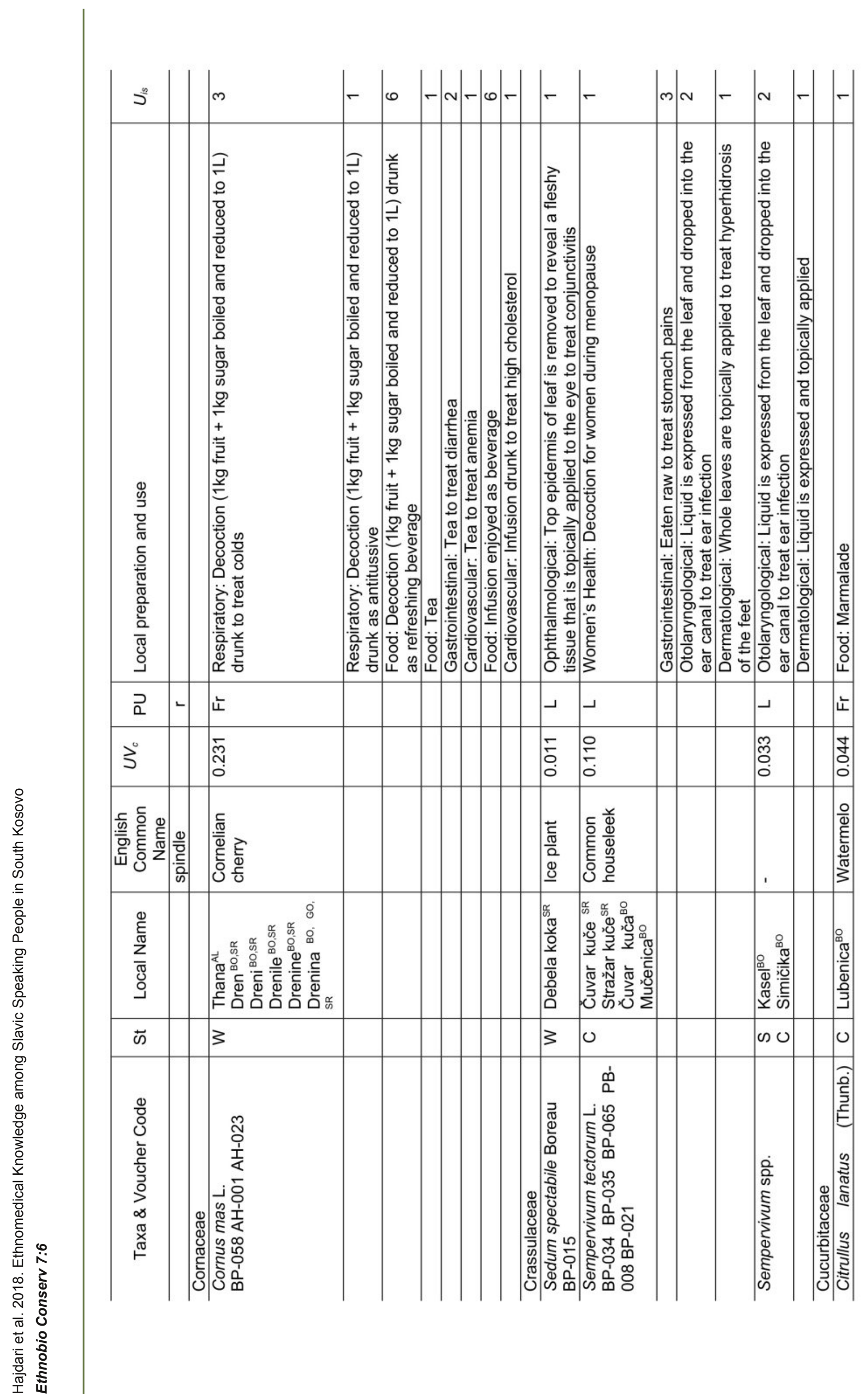




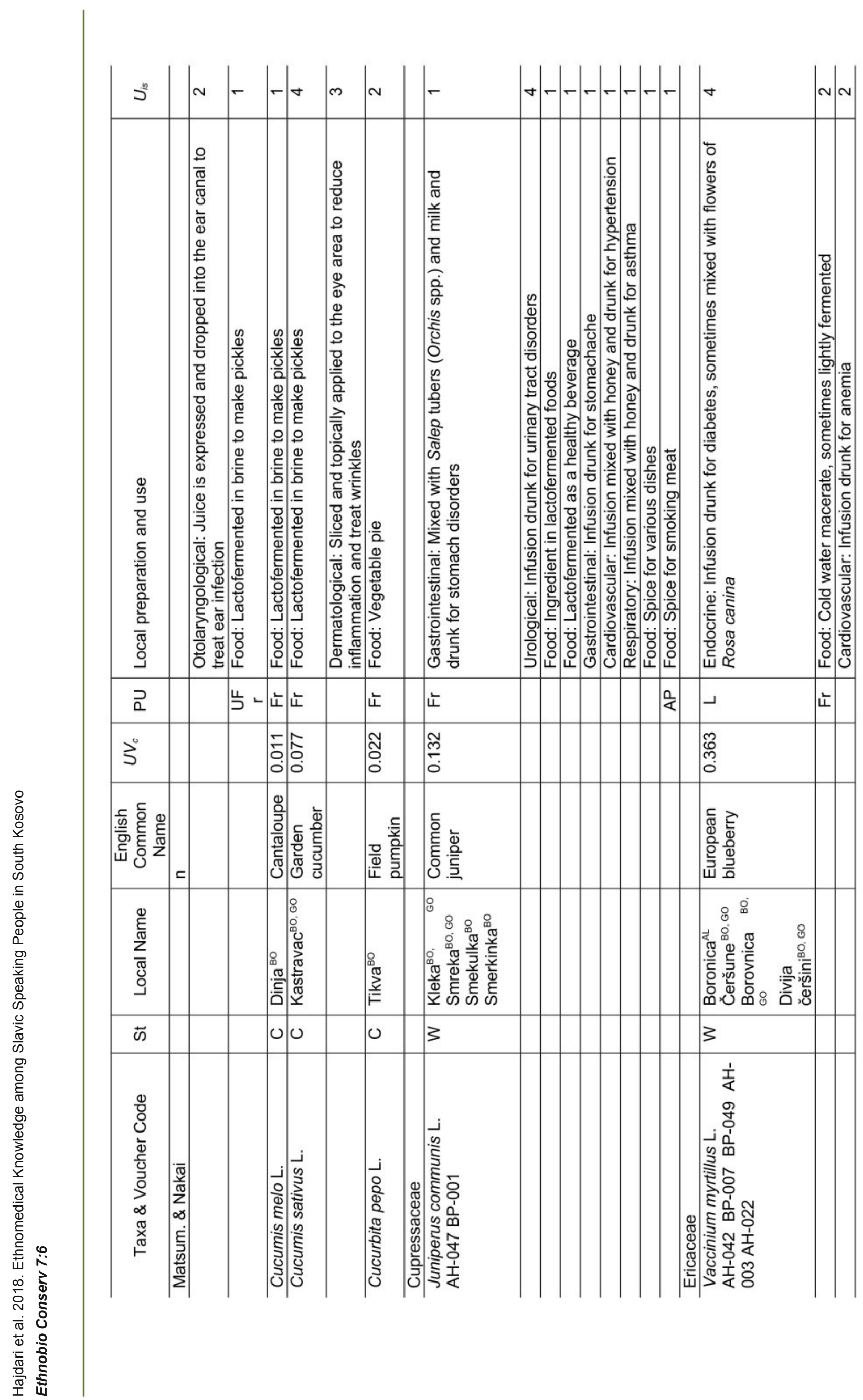




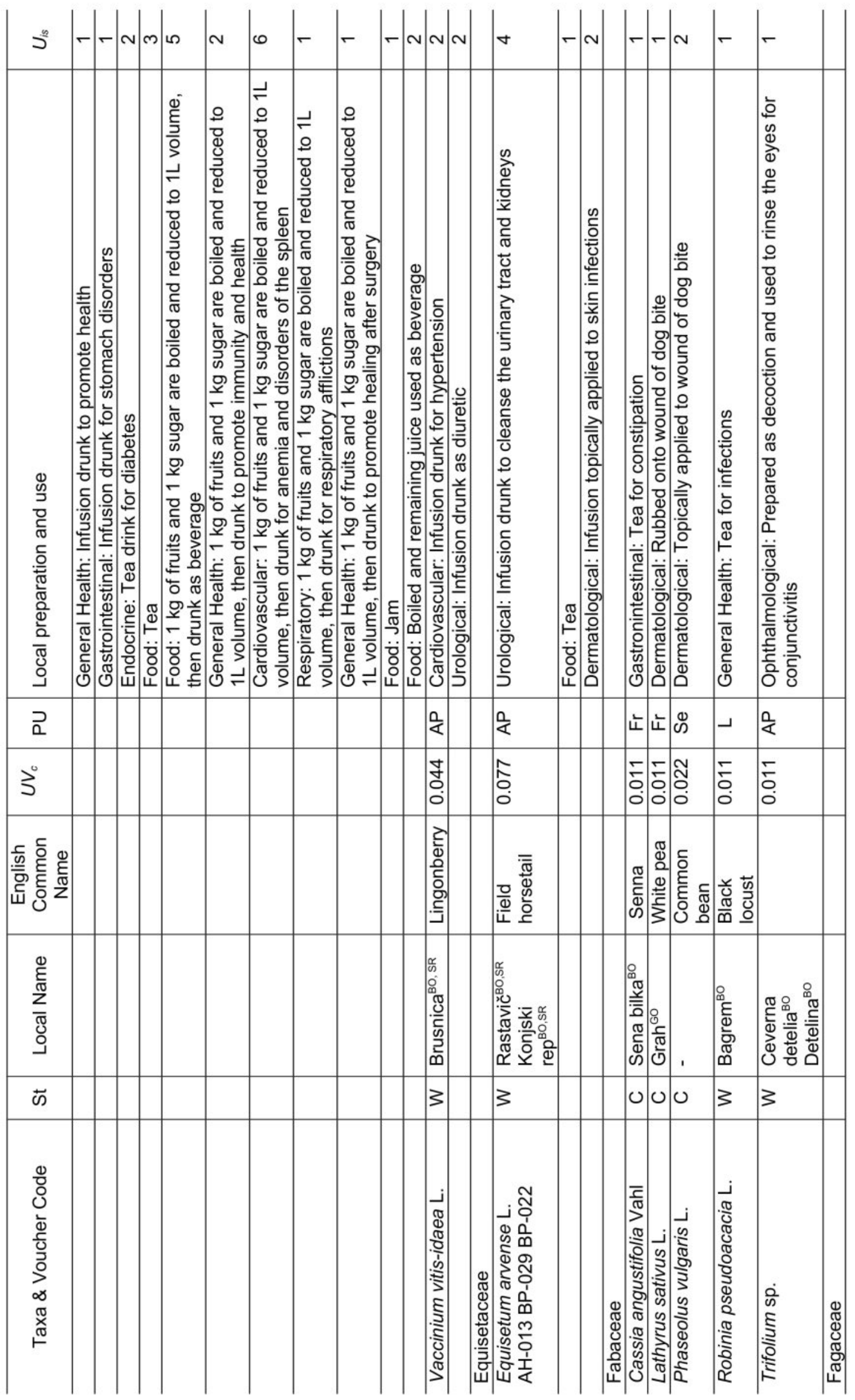




\begin{tabular}{|c|c|c|c|c|c|c|c|c|c|c|c|c|}
\hline$J^{20}$ & - & N & -- & -- & N & $-m$ & $m-$ & $\infty$ & $m-$ & 0 N & $m$ & F \\
\hline 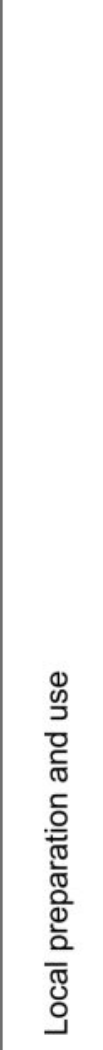 & 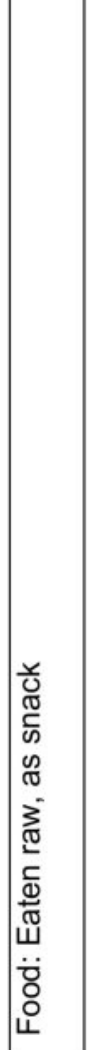 & 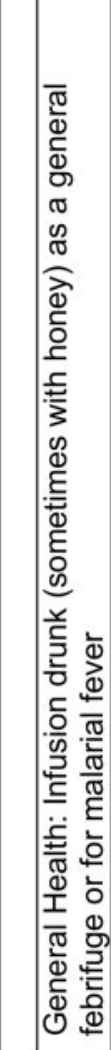 & 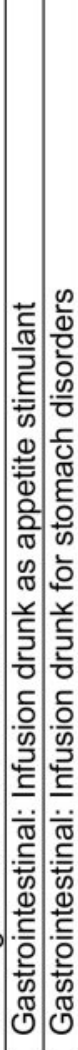 & 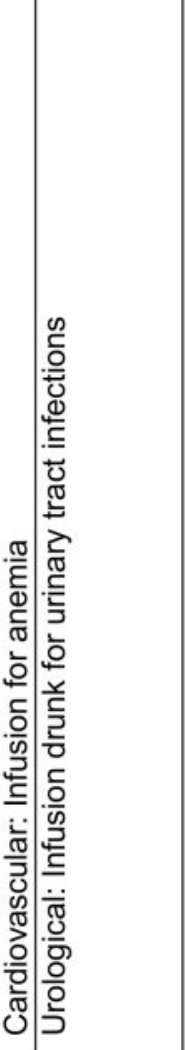 & 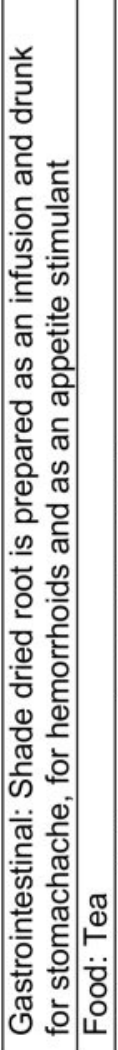 & 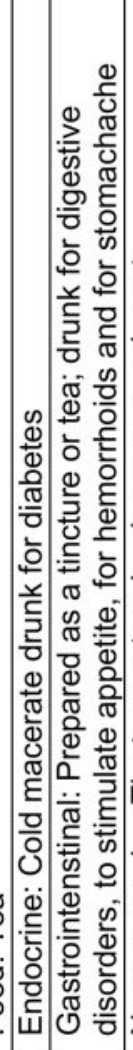 & 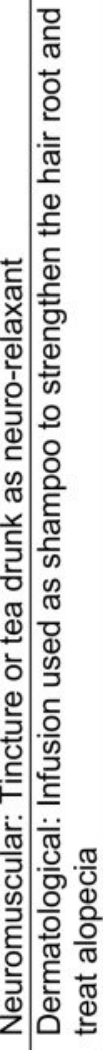 & 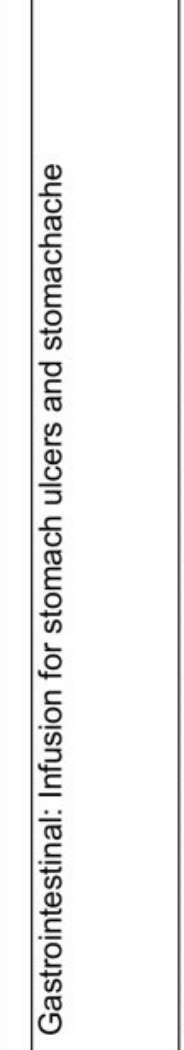 & 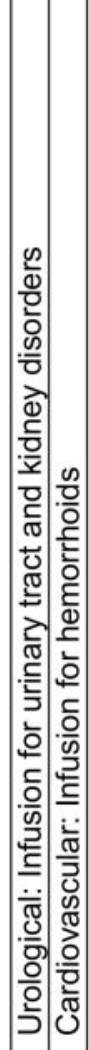 & 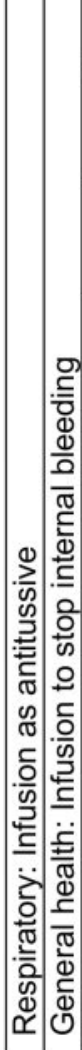 & 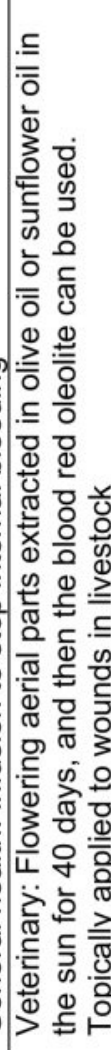 & 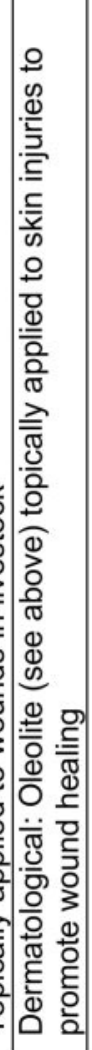 \\
\hline$\stackrel{\partial}{\alpha}$ & ळ & \pm & $\frac{0}{4}$ & பあ & $\stackrel{\leftrightarrow}{\not)}$ & & & $\frac{Q}{\alpha} \subseteq \widehat{\bar{u}}$ & & & & \\
\hline 30 & זٓ & 导 & & 今̂ & & & & 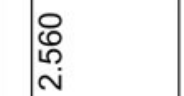 & & & & \\
\hline 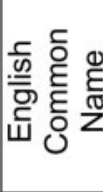 & 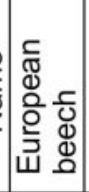 & 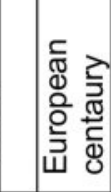 & & 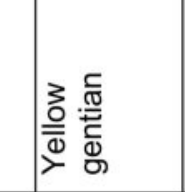 & & & & 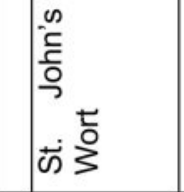 & & & & \\
\hline 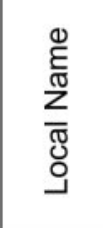 & 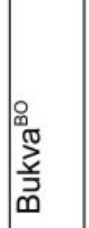 & 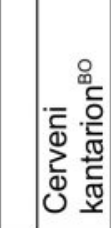 & & 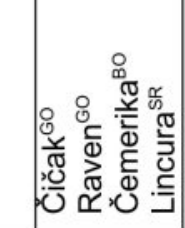 & & & & 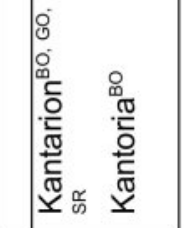 & & & & \\
\hline ๘ & 3 & 3 & & 3 & & & & 3 & & & & \\
\hline 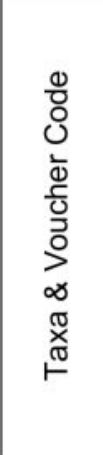 & 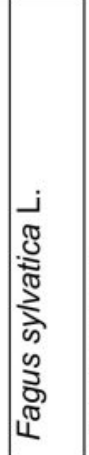 & 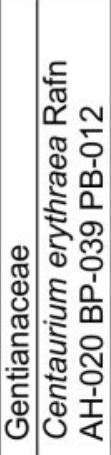 & & 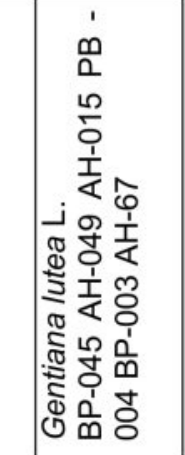 & & & & 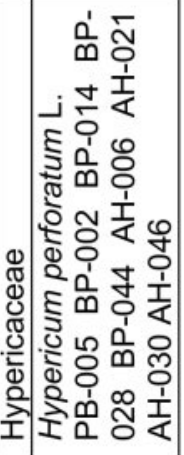 & & & & \\
\hline
\end{tabular}




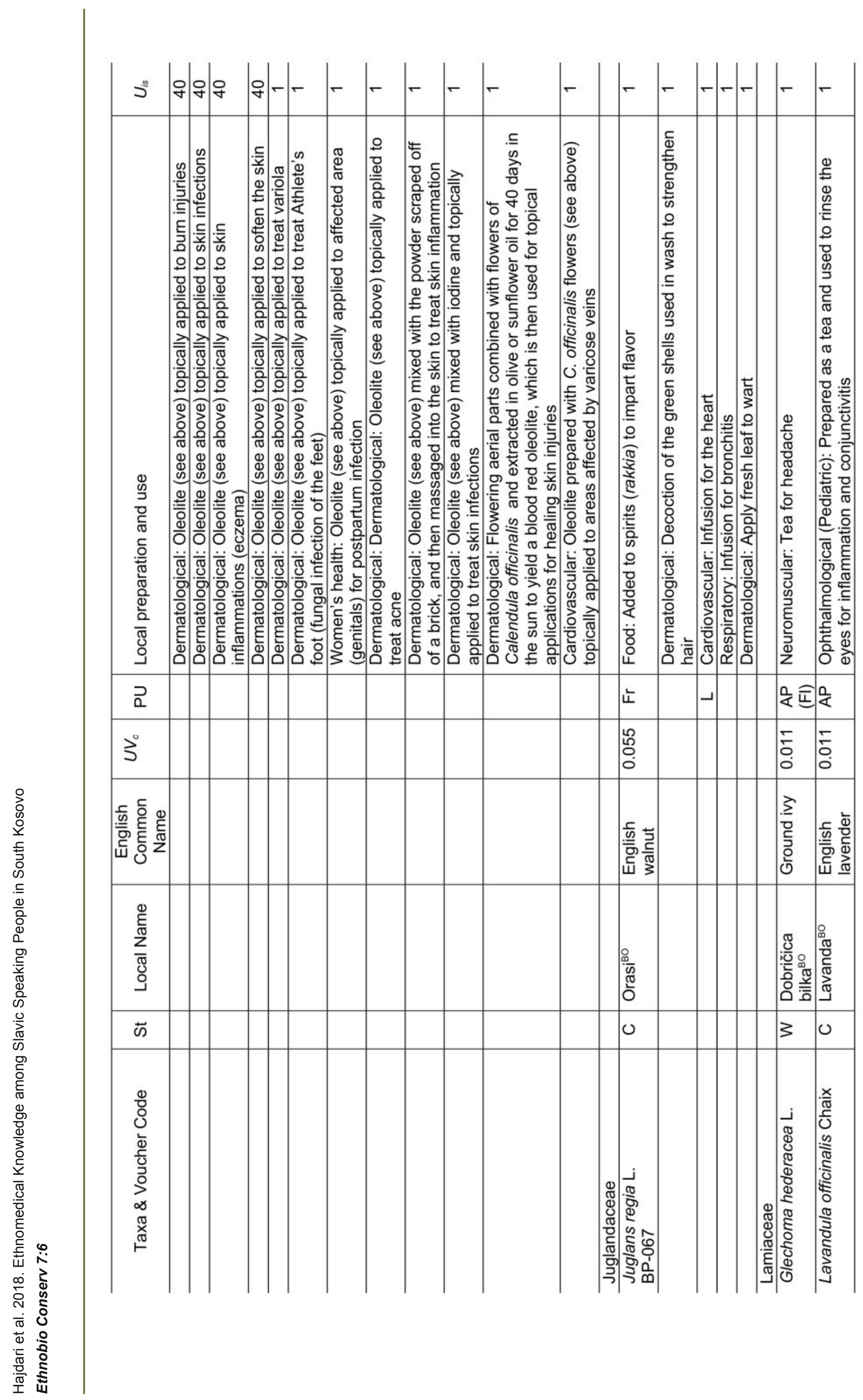




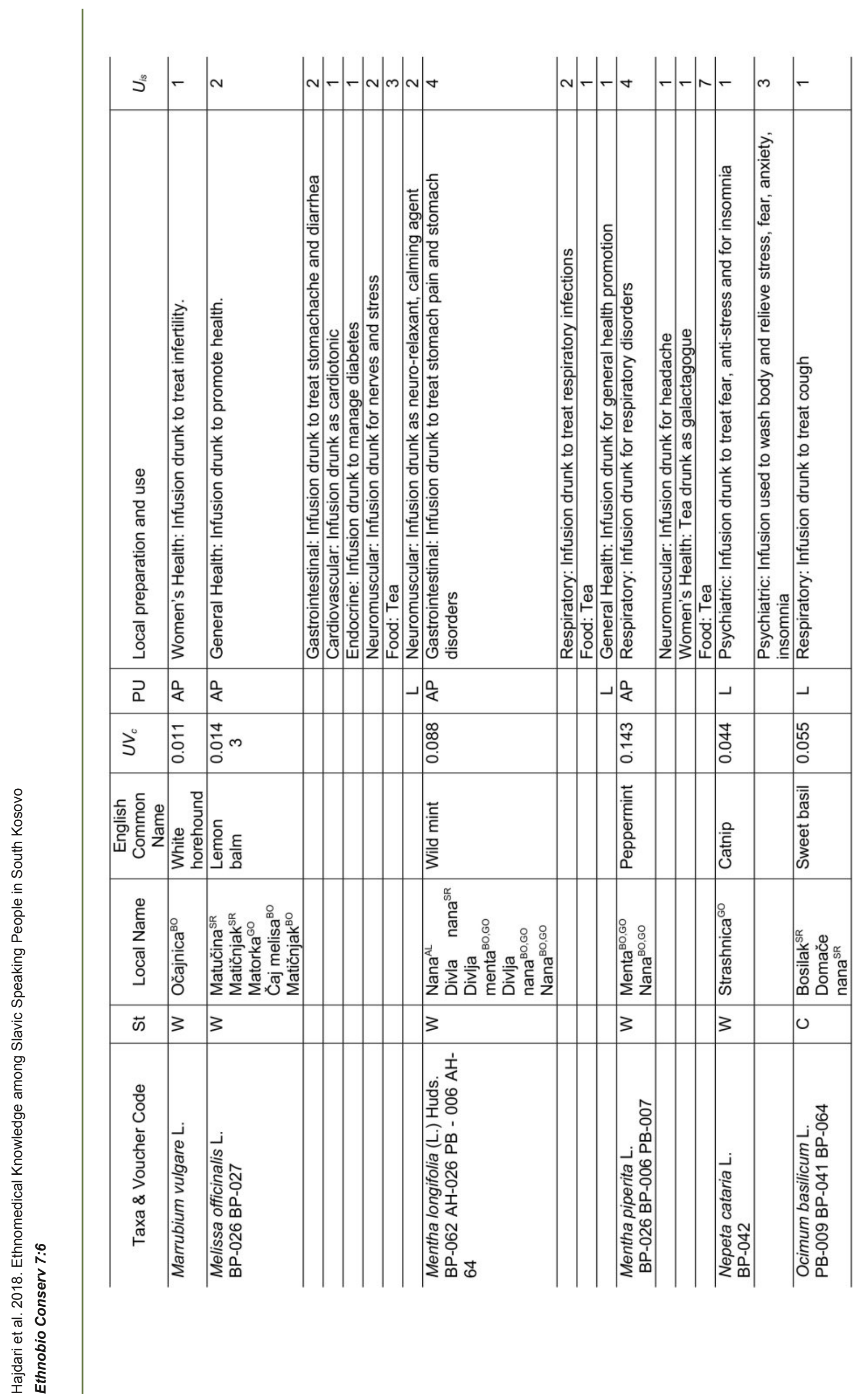




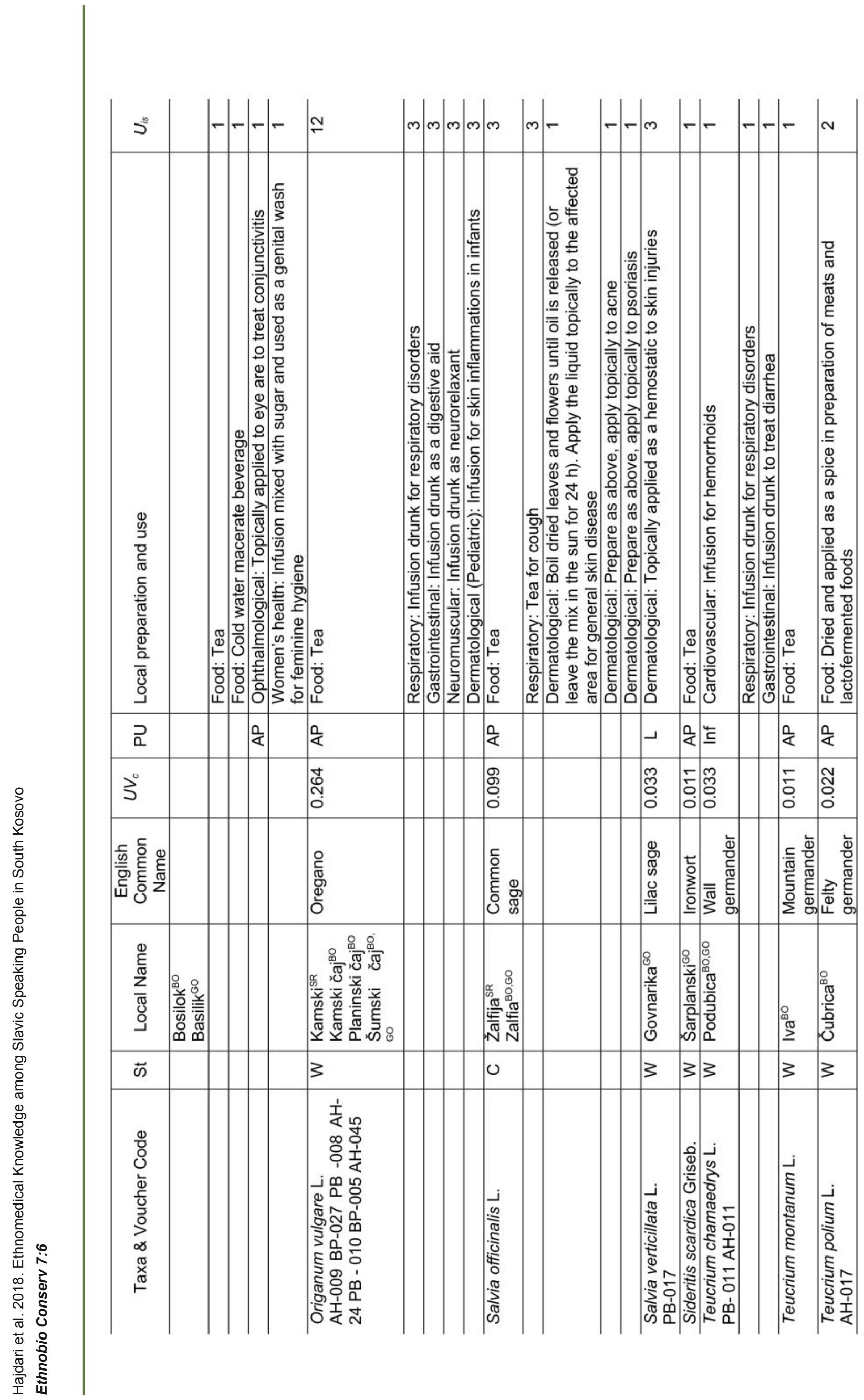




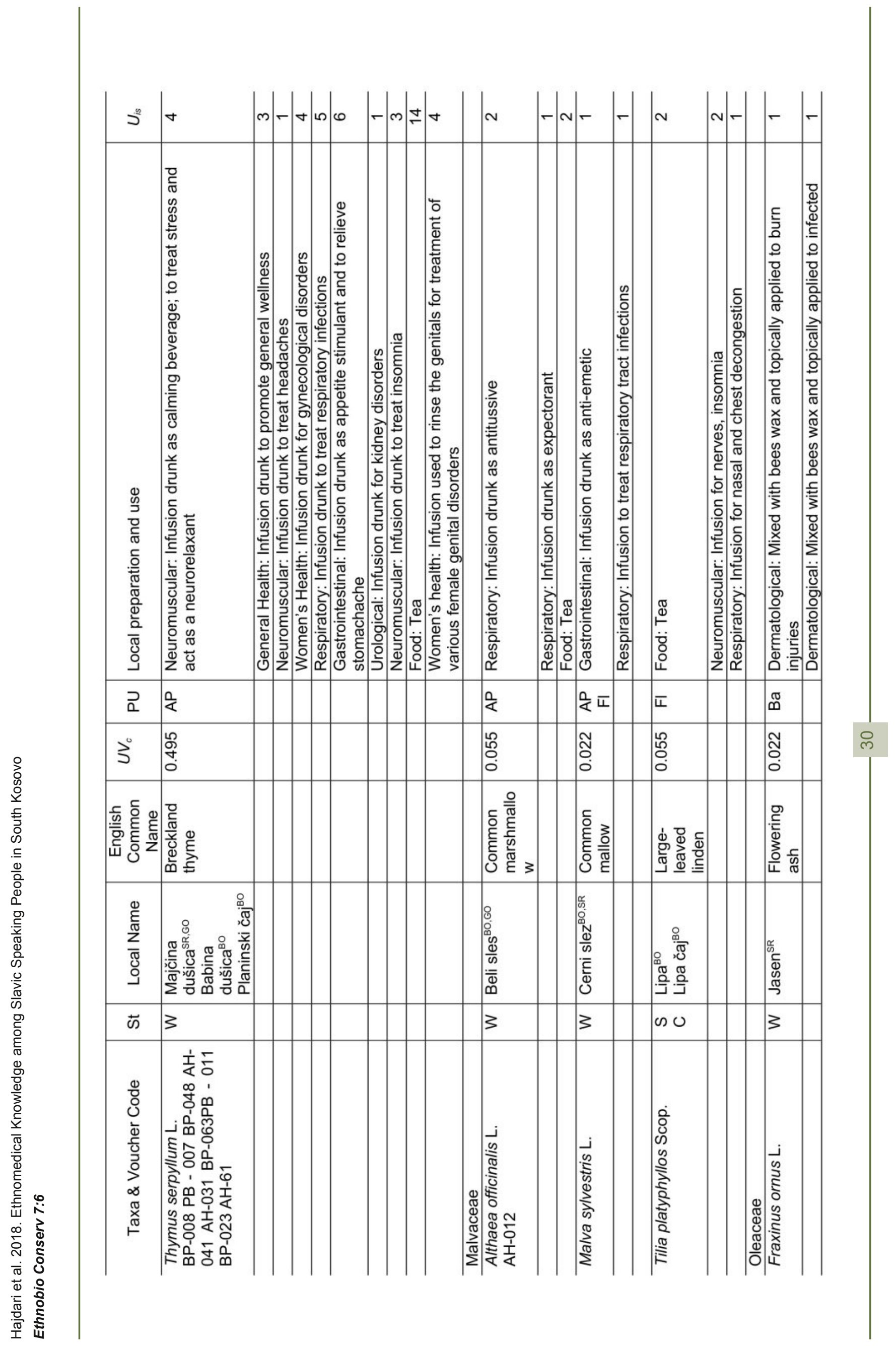




\begin{tabular}{|c|c|c|c|c|c|c|c|c|c|c|c|c|c|c|c|}
\hline$\partial^{\circ 0}$ & $r$ & $\sim$ & $\sim$ & $r$ & $m$ & m & n & - & - & $r$ & $N-$ & & $0 \infty$ & & - \\
\hline 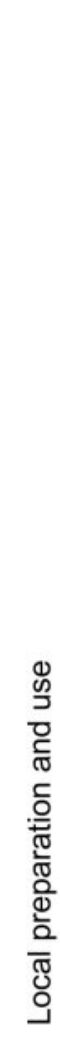 & 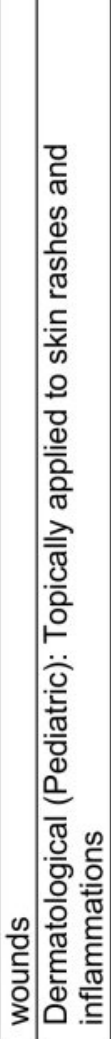 & 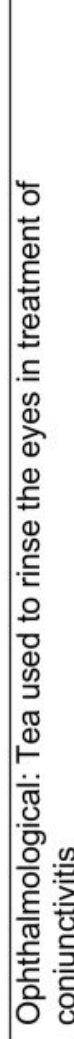 & 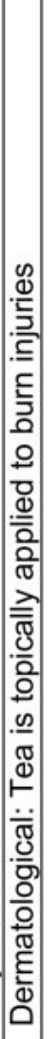 & 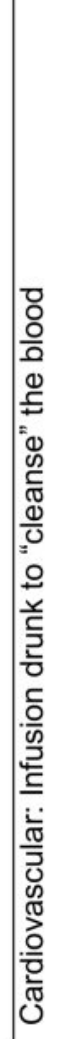 & 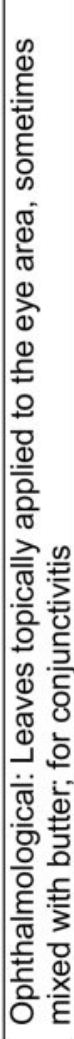 & 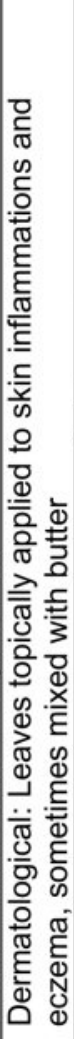 & 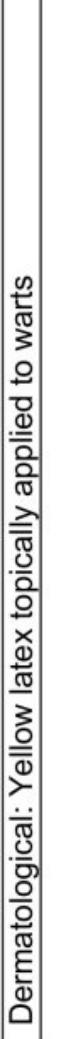 & 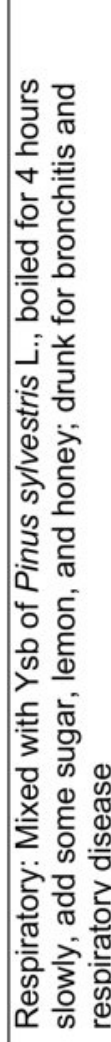 & 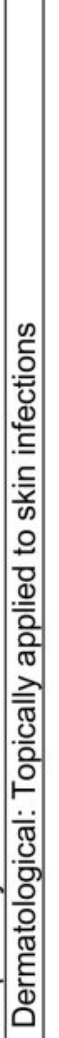 & 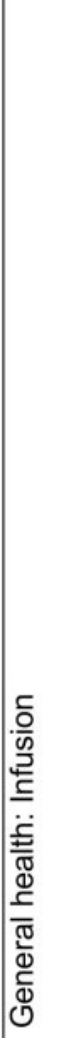 & 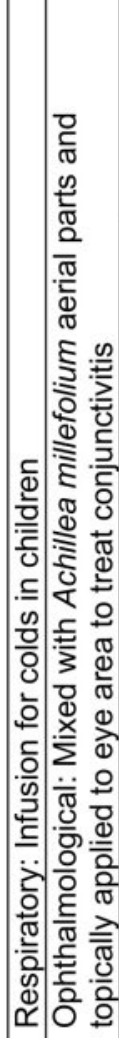 & 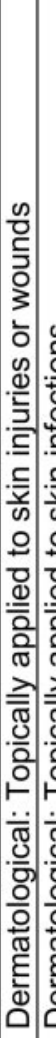 & לֶ. & & 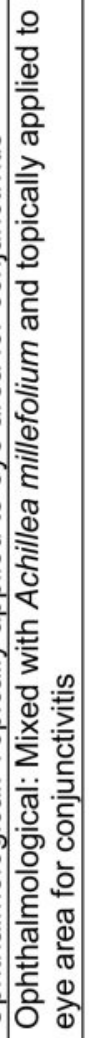 \\
\hline 금 & $\overline{\bar{o}}$ & $\frac{0}{4}$ & & - & & & 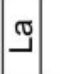 & $\nu^{\infty}$ & \begin{tabular}{|l|}
$\mathscr{\Psi}$ \\
$\propto$
\end{tabular} & \lrcorner & & & & & \\
\hline $3^{\circ}$ & $\underset{0}{\tilde{\sigma}}$ & $\begin{array}{l}\mathbb{Z} \\
\text { Oे } \\
0\end{array}$ & & $\frac{\widetilde{m}}{\stackrel{0}{\circ}}$ & & & & ָ̃ & & \begin{tabular}{l}
$\infty$ \\
\multirow{j}{*}{} \\
0
\end{tabular} & & & & & \\
\hline
\end{tabular}

\begin{tabular}{|c|c|c|c|c|c|}
\hline 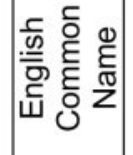 & $\stackrel{\Perp}{\stackrel{\Perp}{\geq}}$ & 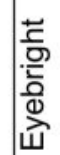 & 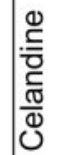 & $\begin{array}{l}\stackrel{0}{\frac{1}{2}} \\
\frac{0}{0} \\
\frac{0}{0} \\
\frac{0}{0}\end{array}$ & 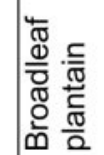 \\
\hline
\end{tabular}

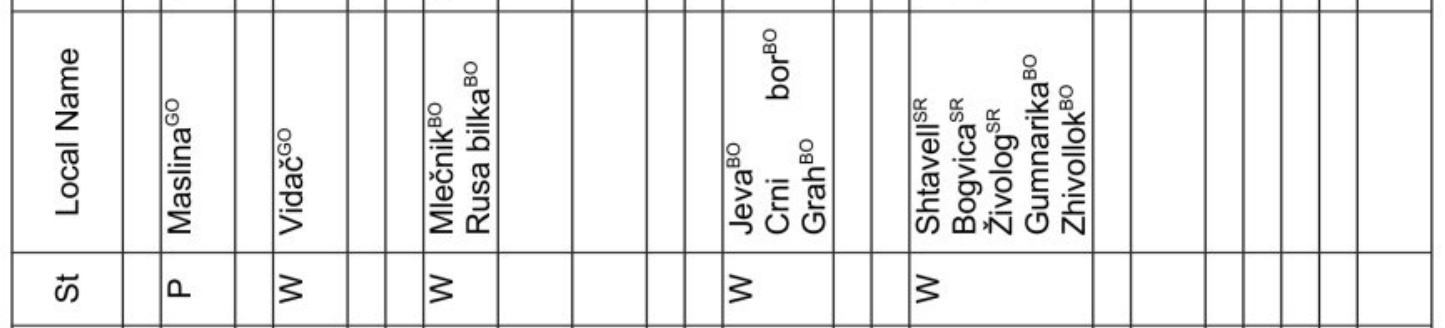

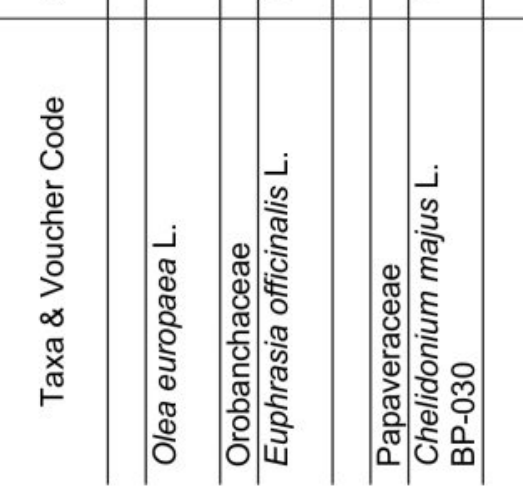

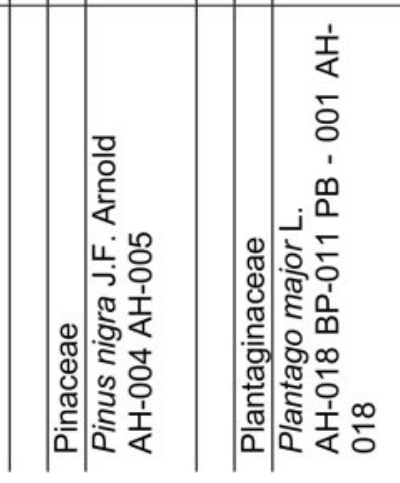




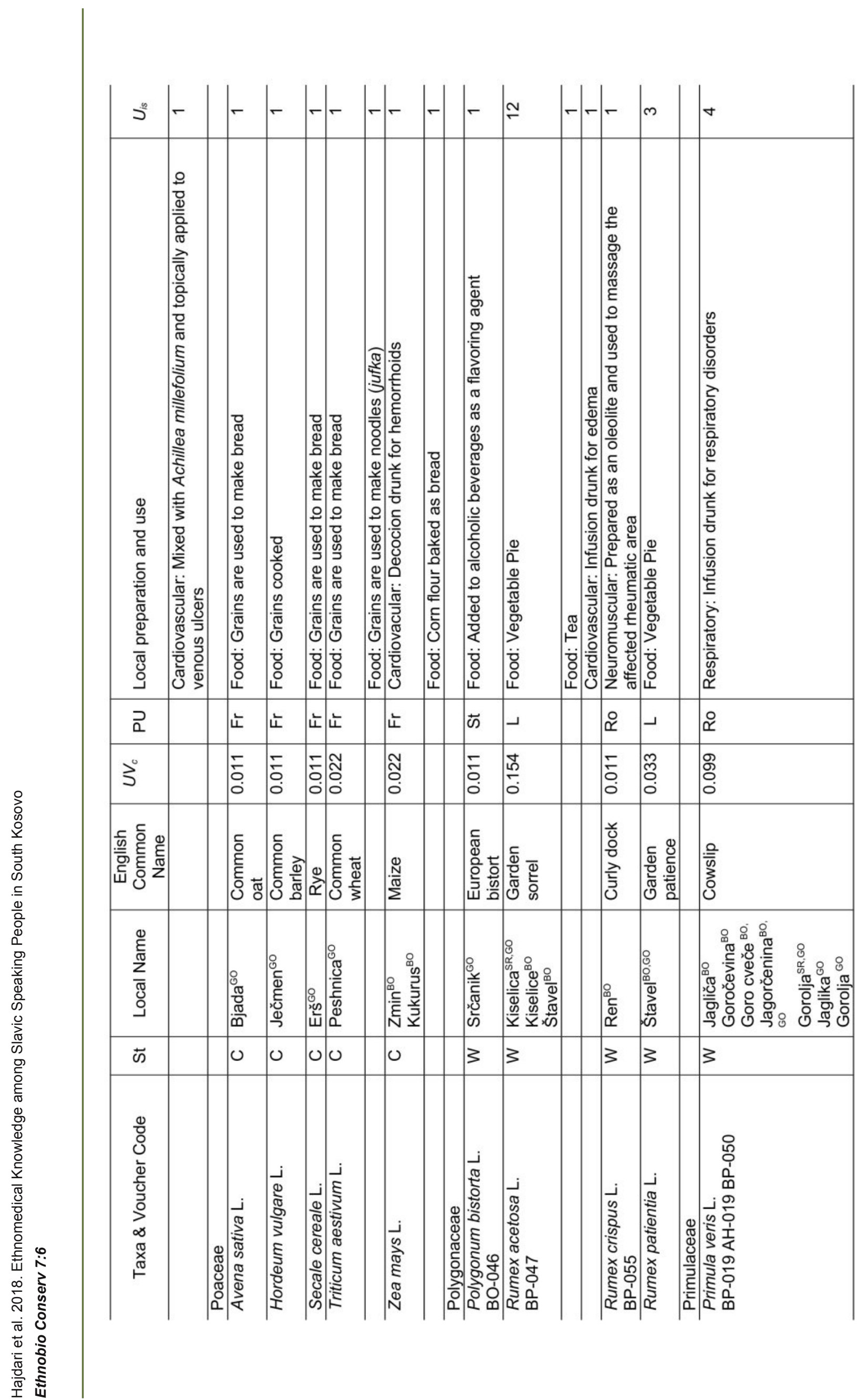




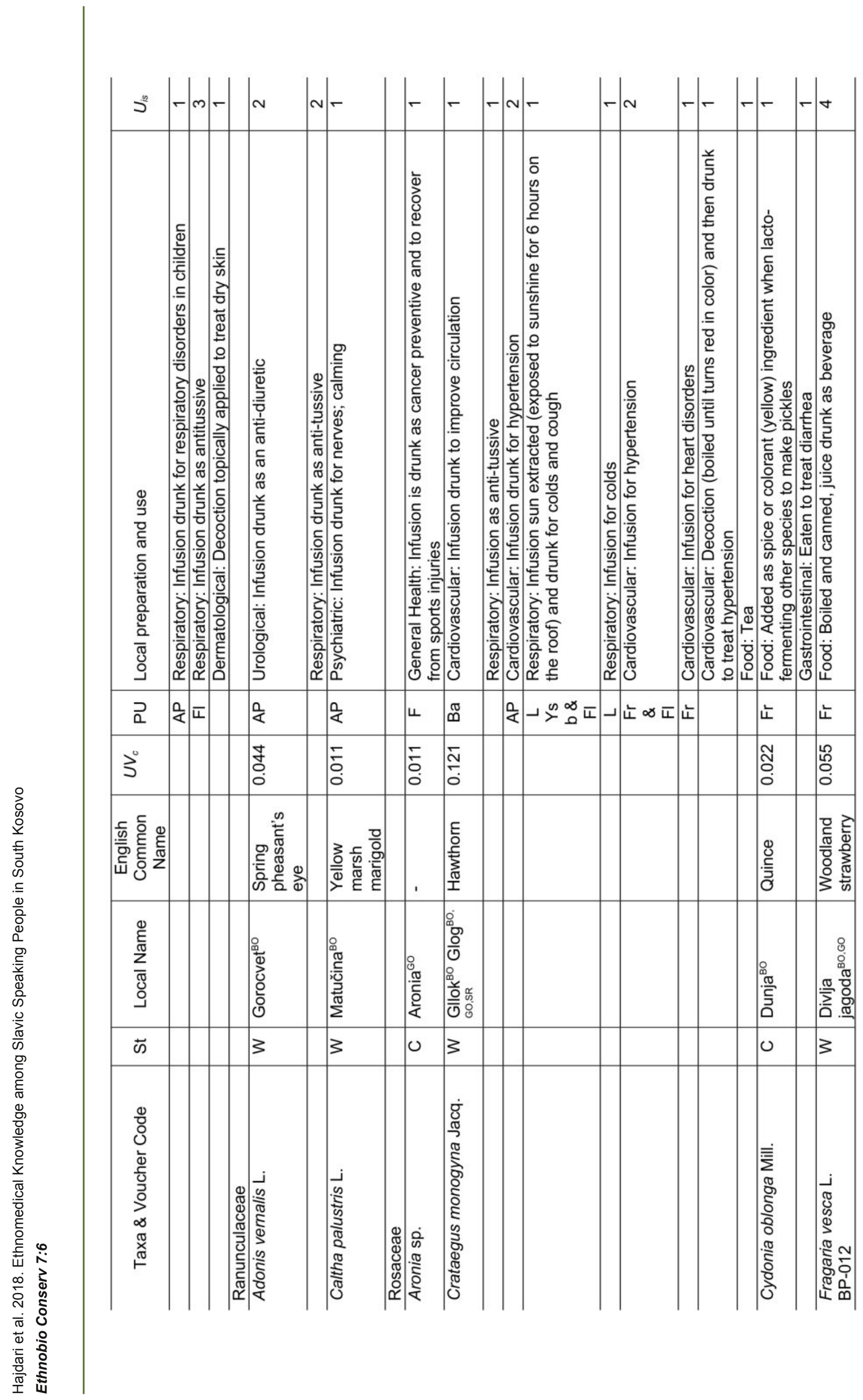




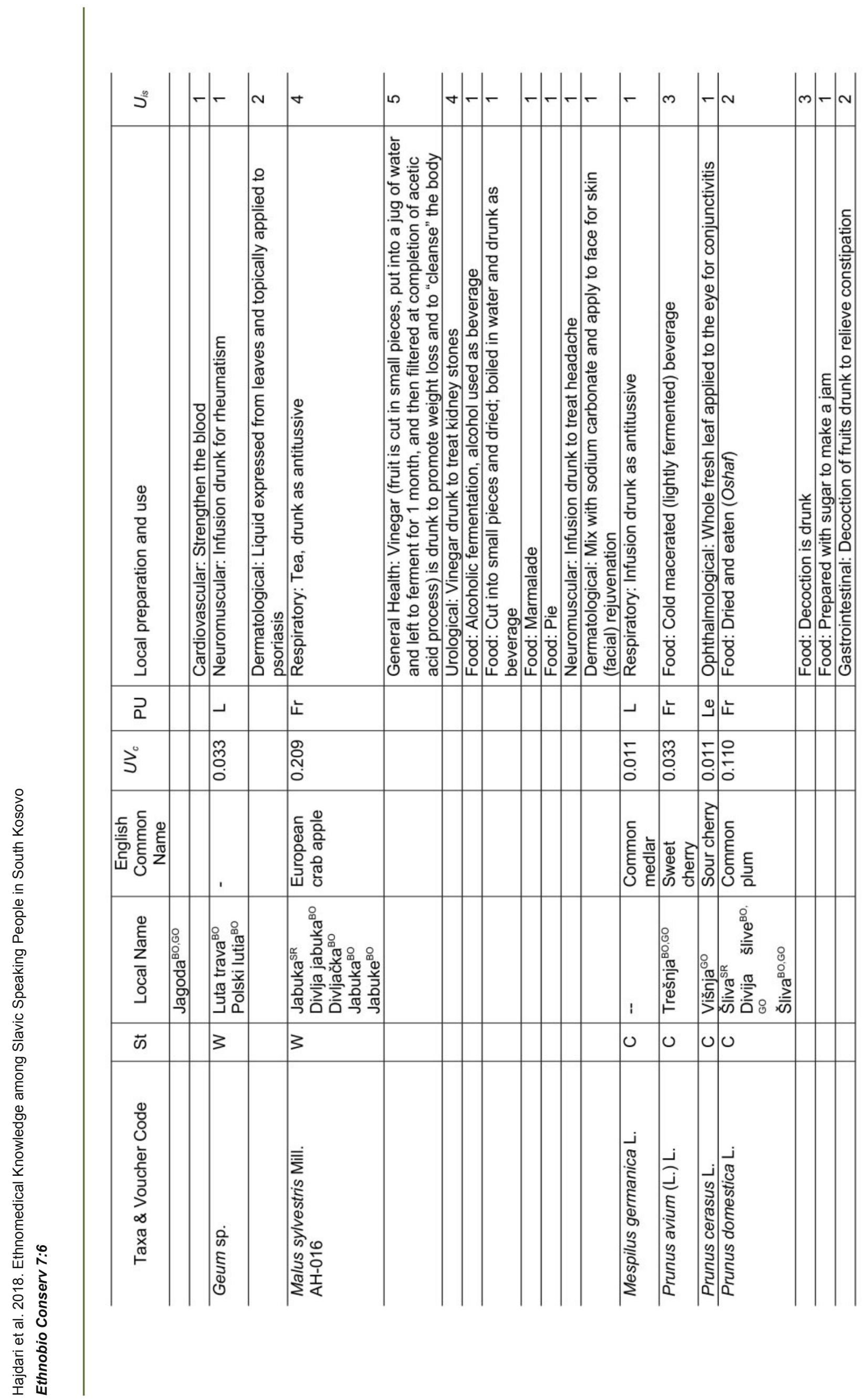




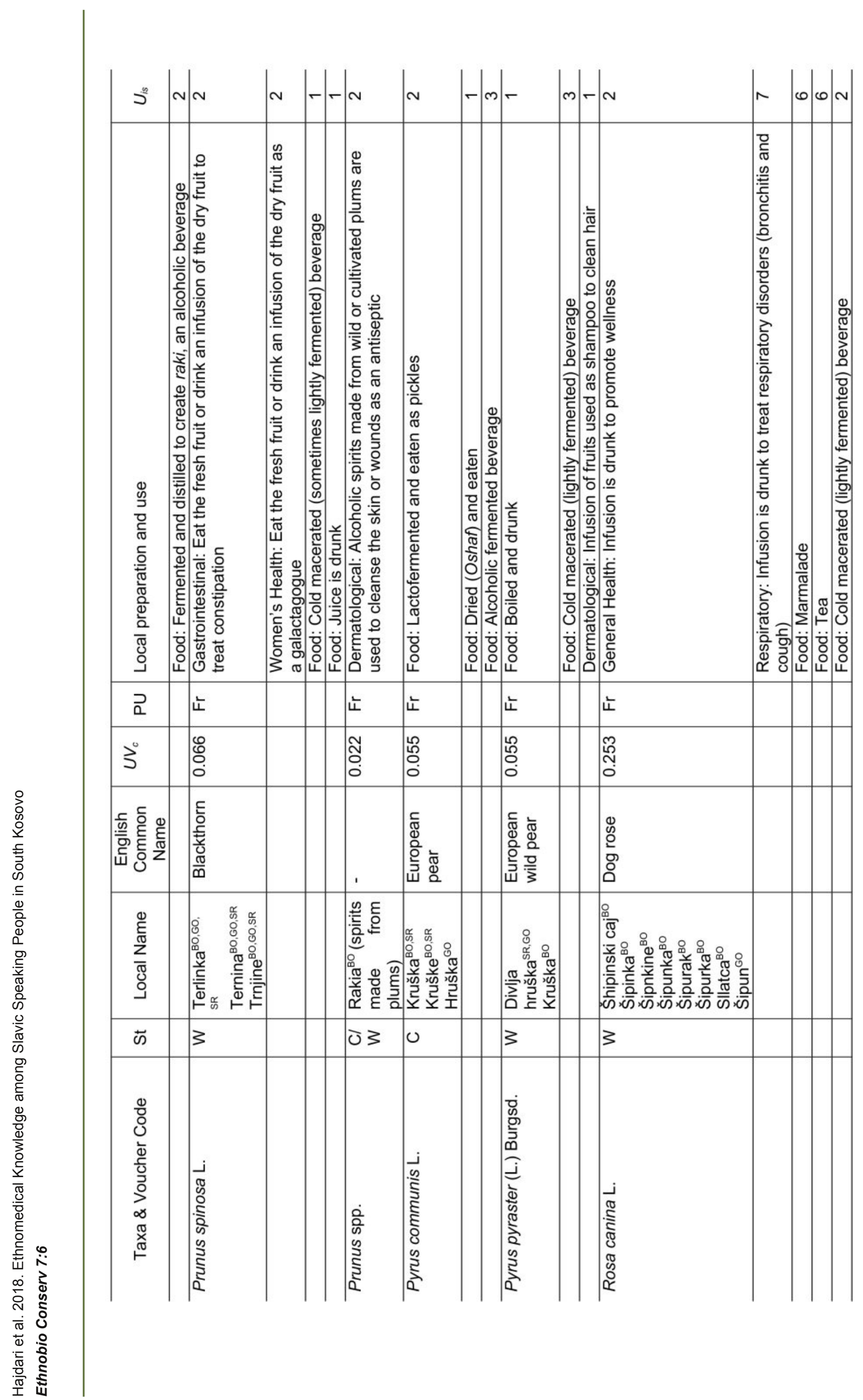




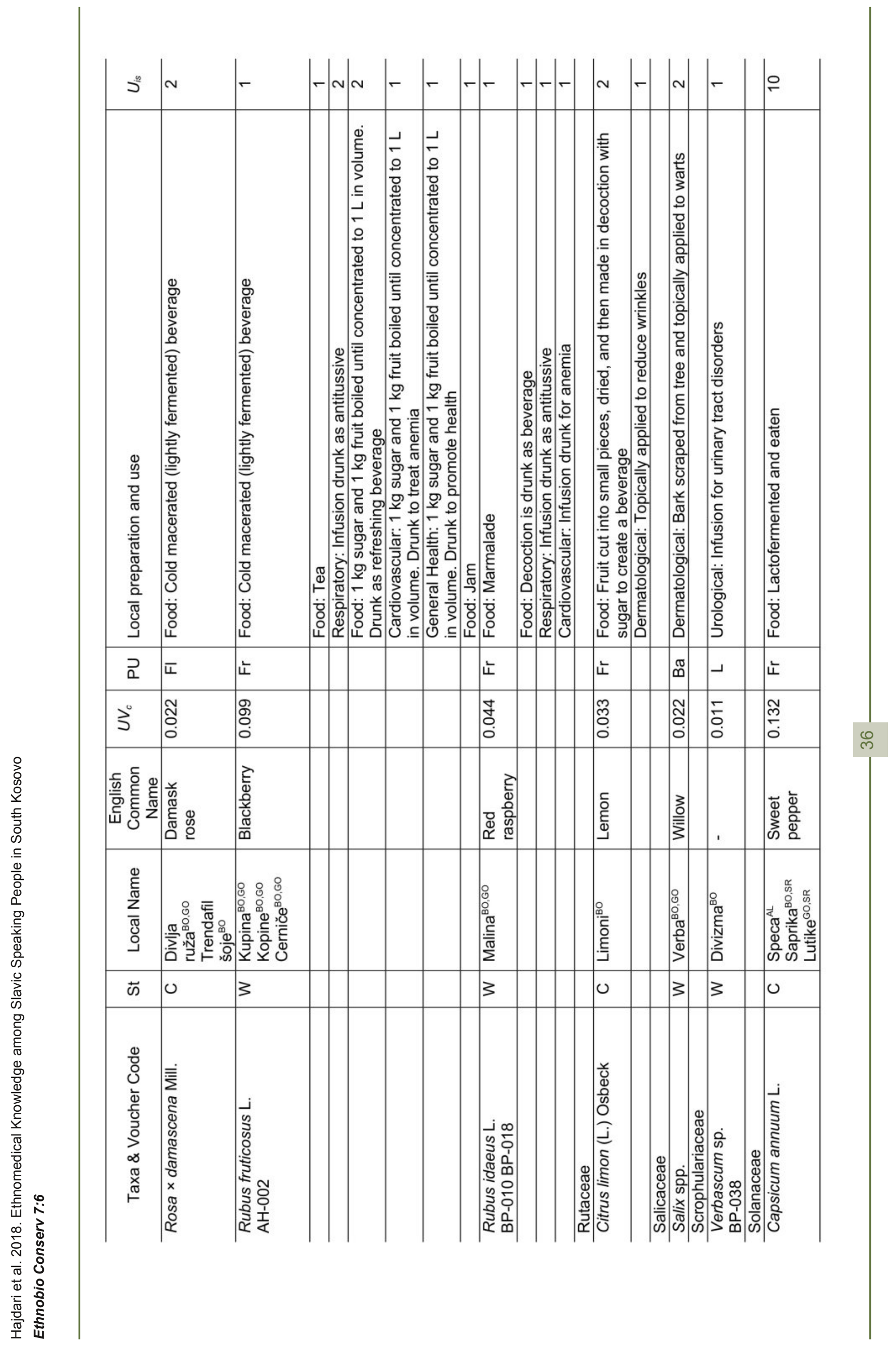




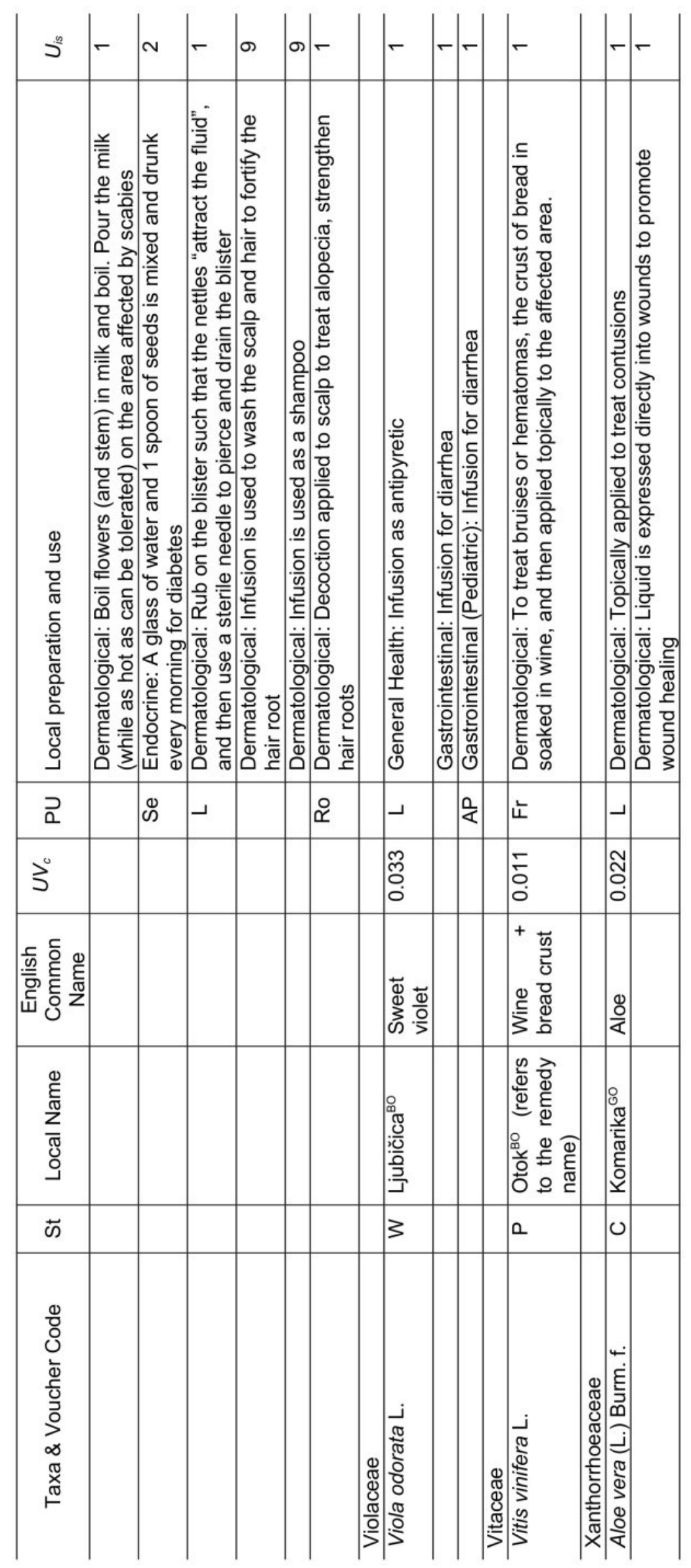




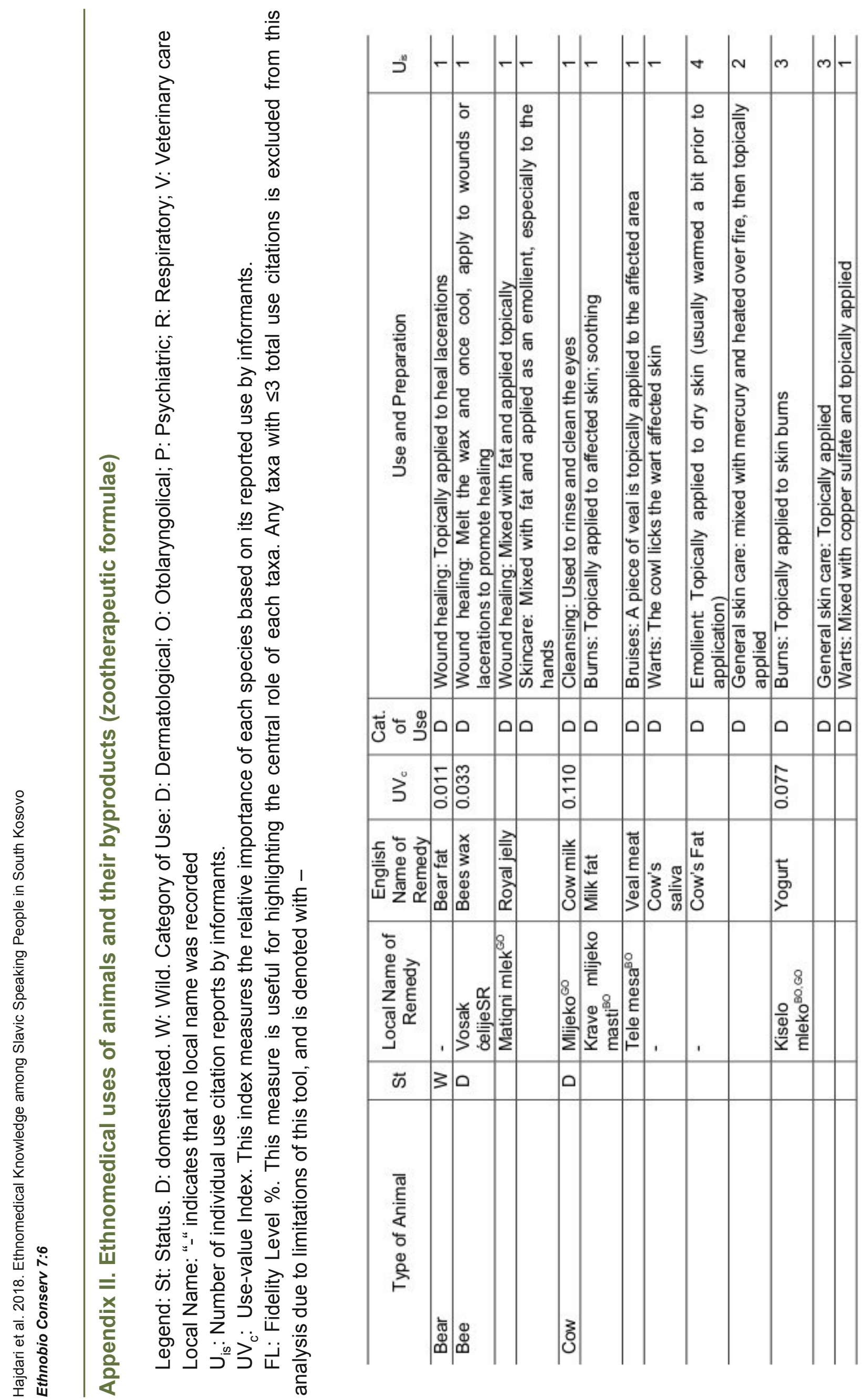




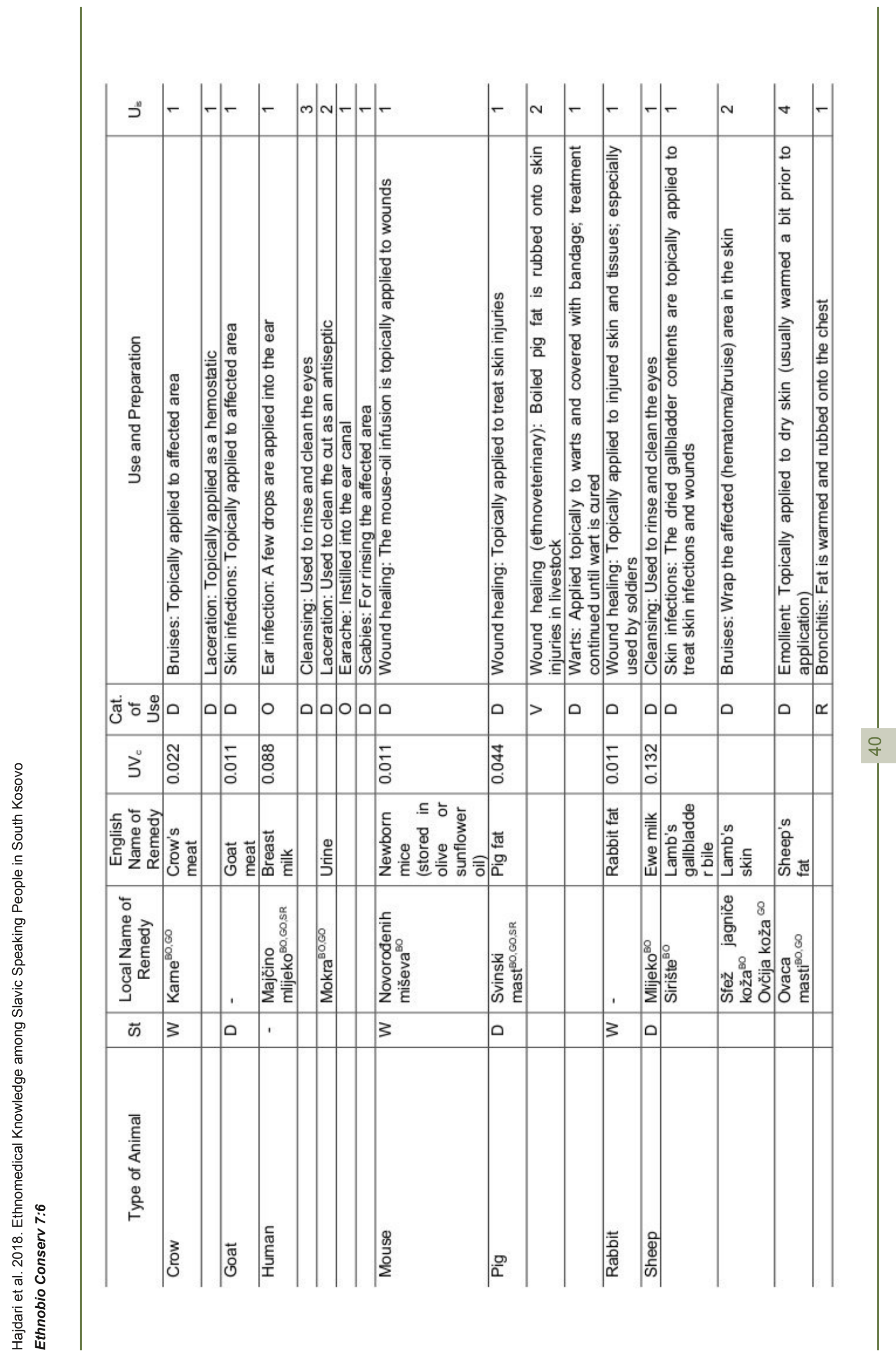




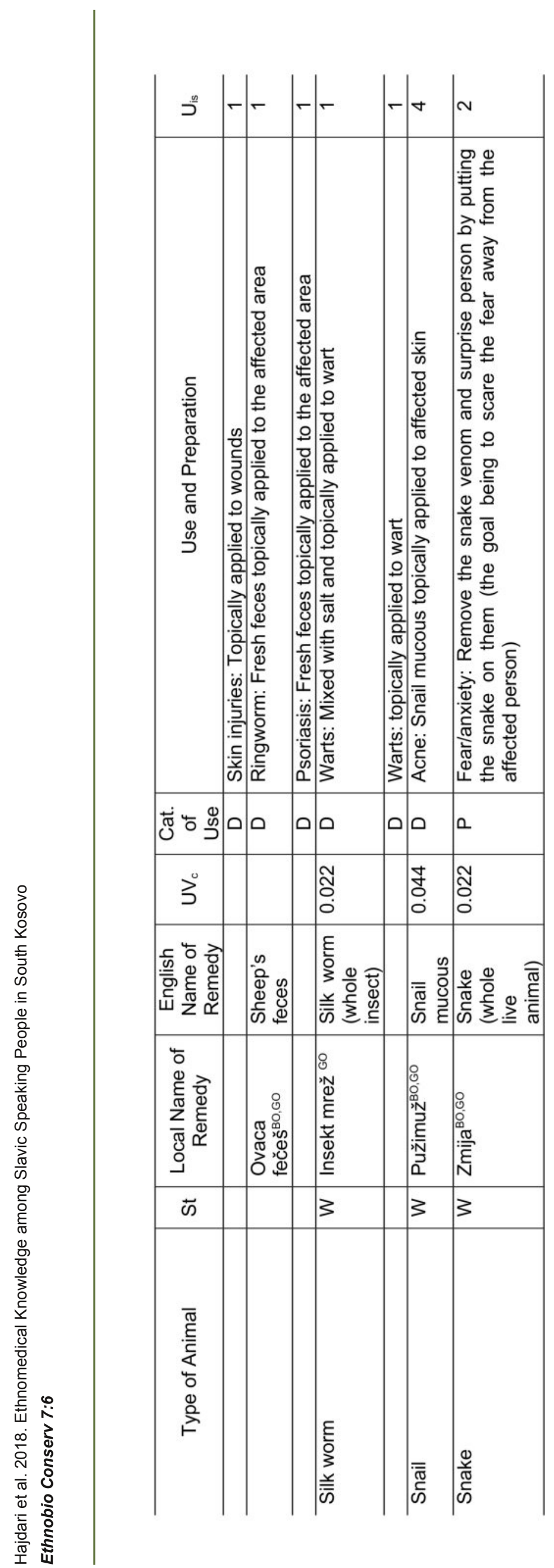




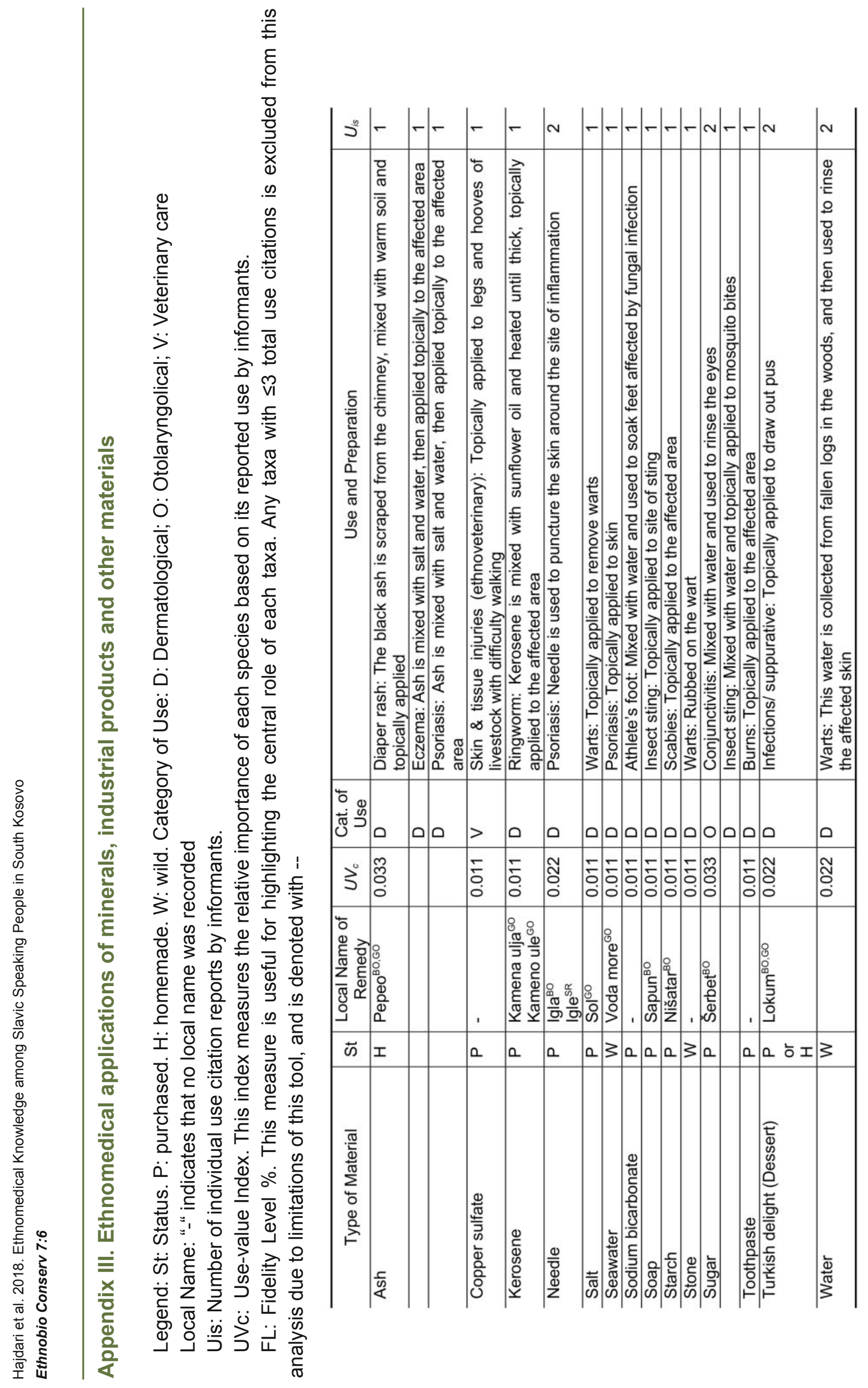

